\title{
Vesicular trafficking and signaling for cytokine and chemokine secretion in mast cells
}

\section{Ulrich Blank 1,2,3 *, Iris Karina Madera-Salcedo ${ }^{1,2,3}$, Luca Danelli ${ }^{1,2,3}$, Julien Claver ${ }^{1,2,3}$, Neeraj Tiwari ${ }^{1,2,3}{ }^{\dagger}$, Elizabeth Sánchez-Miranda ${ }^{4}$, Genaro Vázquez-Victorio ${ }^{4}$, Karla Alina Ramírez-Valadez ${ }^{5}$, Marina Macias-Silva ${ }^{4}$ and Claudia González-Espinosa ${ }^{5 *}$}

\author{
1 INSERM UMRS 1149, Paris, France \\ 2 CNRS ERL8252, Paris, France \\ ${ }^{3}$ Université Paris Diderot, Sorbonne Paris Cité, Laboratoire d'excellence INFLAMEX, Paris, France \\ ${ }^{4}$ Instituto de Fisiología Celular, Universidad Nacional Autónoma de México, México City, México \\ ${ }^{5}$ Departamento de Farmacobiología, Cinvestav, México City, México
}

Edited by:

Paige Lacy, University of Alberta,

Canada

\section{Reviewed by:}

Philippe Georgel, Strasbourg

University, France

Jaya Talreja, Wayne State University,

USA

\section{*Correspondence:}

Ulrich Blank, INSERM UMRS1149,

Université Paris-Diderot, Faculté de

Médecine Site X. Bichat, 16 rue Henri

Huchard, Paris 75018, France

e-mail: ulrich.blank@inserm.fr;

Claudia González-Espinosa,

Departamento de Farmacobiología,

Centro de Investigación y de Estudios

Avanzados del Instituto Politécnico

Nacional, Calzada de los Tenorios 235,

Colonia Granjas Coapa, 14330 México

City, México

e-mail: cgonzal@cinvestav.mx

\section{${ }^{\dagger}$ Present address:}

Neeraj Tiwari, Department of Cell

Biology, Yale University, New Haven,

CT, USA
Upon activation mast cells (MCs) secrete numerous inflammatory compounds stored in their cytoplasmic secretory granules by a process called anaphylactic degranulation, which is responsible for type I hypersensitivity responses. Prestored mediators include histamine and $\mathrm{MC}$ proteases but also some cytokines and growth factors making them available within minutes for a maximal biological effect. Degranulation is followed by the de novo synthesis of lipid mediators such as prostaglandins and leukotrienes as well as a vast array of cytokines, chemokines, and growth factors, which are responsible for late phase inflammatory responses. While lipid mediators diffuse freely out of the cell through lipid bilayers, both anaphylactic degranulation and secretion of cytokines, chemokines, and growth factors depends on highly regulated vesicular trafficking steps that occur along the secretory pathway starting with the translocation of proteins to the endoplasmic reticulum. Vesicular trafficking in MCs also intersects with endocytic routes, notably to form specialized cytoplasmic granules called secretory lysosomes. Some of the mediators like histamine reach granules via specific vesicular monoamine transporters directly from the cytoplasm. In this review, we try to summarize the available data on granule biogenesis and signaling events that coordinate the complex steps that lead to the release of the inflammatory mediators from the various vesicular carriers in MCs.

Keywords: mast cells, signaling, vesicular trafficking, secretion, inflammation

\section{INTRODUCTION}

Mast Cells (MCs) are tissue cells that are well known effectors in IgE-mediated allergic or anti-parasitic responses, but research in the last two decades has revealed that they are also important participants in innate immunity and inflammation $(1,2)$. One of their prime functions is to release a large array of inflammatory mediators, which mediate tissue responses, participate in immunoregulatory and inflammatory processes as well as tissue remodeling (2-5). These mediators include compounds prestored in a release-ready form in their cytoplasmic secretory granules (SGs) such as histamine and MC specific proteases. MC also secrete newly synthesized lipid mediators such as leukotrienes or prostaglandines or a variety of cytokines, chemokines, and growth factors $(3,6)$. While synthesized lipid compounds freely diffuse across the membrane, the release of protein products depends on vesicular carriers and membrane fusion $(7,8)$.

Study of the biologic function and involved signaling pathways engaged by various membrane receptors has evidenced that MC can release either their full array of mediators or just some of them under particular conditions of stimulation (9). For example, while stimulation through the IgE Fc receptor (FceRI) generally leads to a full response, stimulation through Toll-like receptor 2 and 4 (TLR2 and TLR4) or through some cytokine receptors induces the selective release of newly synthesized chemokines and cytokines in the absence of degranulation (9). The release characteristics also depend on the strength of stimulus as, for example, after weak stimulation (low antigen concentration in case of Fc\&RI) the release of chemokines over cytokines is favored (10). This is due to the engagement of different signaling pathways that at least in part imply engagement of distinct Src-related kinases (11).

Research in recent years on secretory mechanisms after stimulation has mostly focused on the degranulation process that concerns the release of mediators stored in cytoplasmic granules, which amongst many other compounds includes also certain cytokines (4). At present, little is known on the vesicular trafficking of newly synthesized cytokines and chemokines and its positive and/or negative regulation. Yet, it is clear that like secretion from cytoplasmic granules the release of newly synthesized 


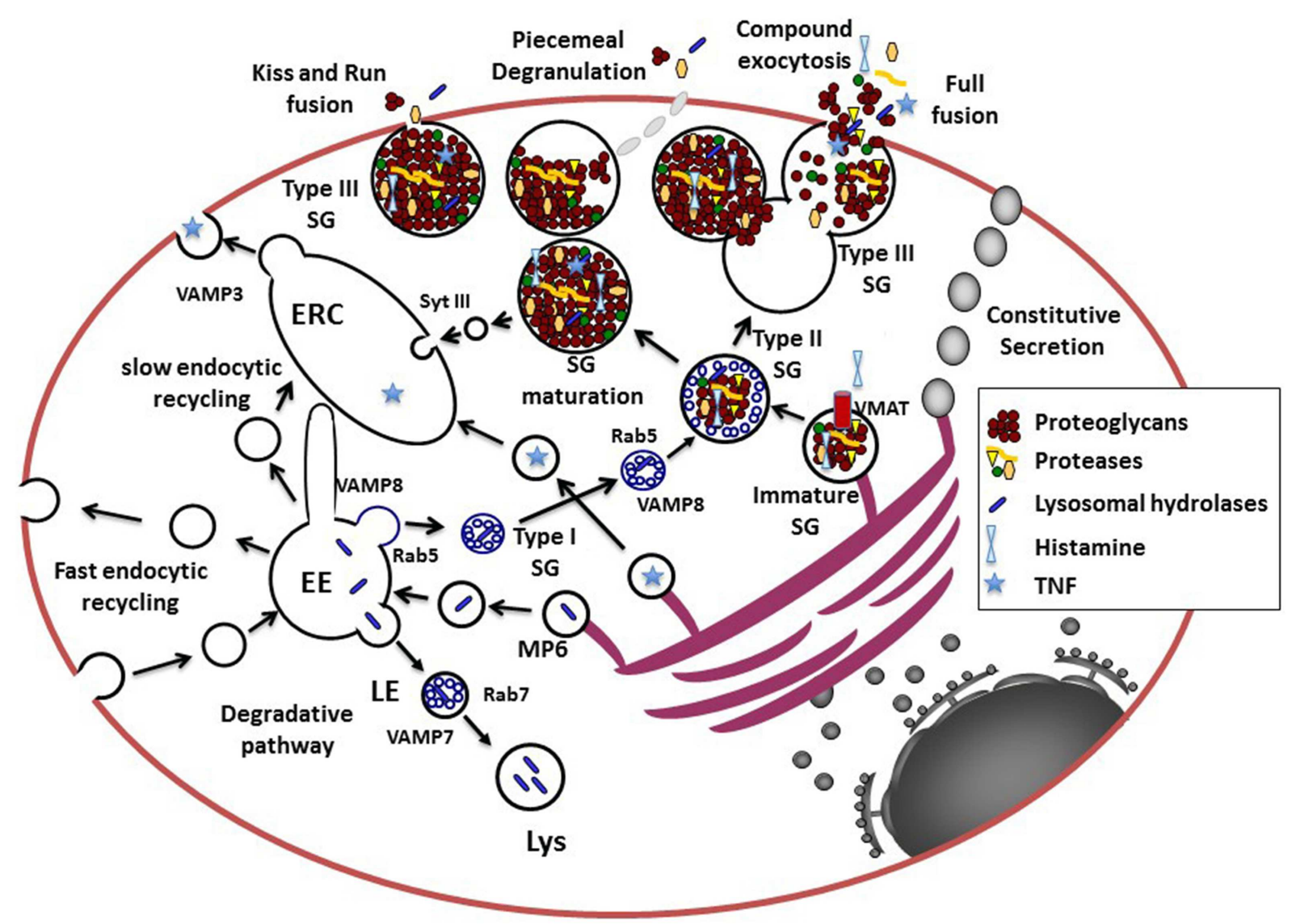

FIGURE 1 | Model for the secretory pathways in MC. Newly synthesized proteins destined for secretion enter the secretory pathway at the rough ER. After passage through the Golgi where posttranslational modifications occur, they reach the trans-Golgi network (TGN), which functions as a sorting hub depending on various structural motifs. For example, $\mathrm{GPI}$-anchored or $\mathrm{N}$-and $\mathrm{O}$-glycosylated proteins enter the constitutive secretory pathway for trafficking to the cell surface. Proteins destined for the endosomal-lysosomal pathway are modified by Mannose- 6 phosphate (MP6) for recognition by the Mannose-6-phosphate receptor that via an acidic cluster/dileucine motif is delivered to the early endosome (EE). Together with endocytosed proteins destined for degradation they are further sorted to late endosomes (LE) forming multivesicular structures and then fuse with lysosomes (Lys) via a VAMP-7 and Rab7-dependent pathway. Some proteins, like for example, newly synthesized TNF may be sorted into vesicles to reach the endocytic recycling compartment (ERC) from where it could be secreted. The ERC may serve as an additional sorting hub for the exocytosis and recycling of proteins via retrograde pathways (not shown in this figure). The cytoplasmic SG, which contain proteins destined for the regulated secretory pathway for release upon stimulation in $\mathrm{MC}$ and other hematopoietic cells are so-called mixed type organelles or secretory lysosomes carrying features of endosomes and lysosomes. Proteins destined for SG may leave the TGN at sites where larger protein aggregates are formed possibly via association to highly negatively charged proteoglycans. The immature SG formed may then rapidly fuse with carriers (type I SG) containing small intraluminal vesicles derived from the early endosome via a Rab5 and VAMP-8 dependent mechanism to form type II SG. Some inflammatory mediators like histamine incorporates into SG via specific vesicular monoamine transporters (VMAT). SG then undergo a maturation process, which generates mature type III SG by the retrieving cargo of missorted proteins and intraluminal vesicles to the ERC.

Pre-formed inflammatory mediators can then be released via several types of fusion processes including transient kiss-and-run fusion, piecemeal degranulation, or multigranular/compound exocytosis, which involves full fusion and collapse of SG. It is possible that during stimulation all types of granules (type I, II, and III) are fusion competent as suggested by the fact that cultured cells with less mature granules can be stimulated for release. chemokines, cytokines, and growth factors must be tightly regulated to ensure an appropriate biological response. Here, we review some of the important aspects of the vesicular trafficking mechanisms and their involvement in MC cytokine and chemokine secretion.

\section{SECRETORY PATHWAYS IN MC}

In MC, like in any other cell type, the secretory pathway (Figure 1) starts with the translocation of nascent signal-peptide containing proteins at the rough endoplasmic reticulum (ER) after recognition by the cytosolic signal-recognition particle (SRP) ribonucleoprotein complex, which binds to the ER-localized SRPreceptor (12). From the ER, the proteins sequentially travel through the Golgi stacks via a still not completely understood process involving either Golgi cisternal maturation or vesicular transport carriers (13). While passing the Golgi stacks posttranslational modifications occurs, such as for example, glycosylation, and proteins finally reach the Trans-Golgi network (TGN). The TGN functions as a sorting hub for protein trafficking (14-16). By default, via the constitutive secretory pathway, glycosylated or 
glycosylphosphatidylinositol (GPI)-anchored proteins are delivered to the plasma-membrane (PM) via tubular-vesicular carriers that bud off from the ER by a well regulated process involving motor proteins and fission processes and then fuse with the PM (16). However, in the presence of specific sorting signals (sorting by exit) proteins may be routed to other intracellular compartments. For example, within the Golgi apparatus, lysosomal hydrolases acquire a mannose-6-phosphate (M6P) moiety (17). M6P is then recognized by the $\mathrm{M} 6 \mathrm{P}$ receptor (M6PR) at the TGN. An acidic cluster/dileucine motif in the cytoplasmic tail of the M6PRs then serves as a sorting signal for specific adaptor proteins (such as AP-1) allowing packing into clathrin-coated transport vesicles targeting them to early endosomes (16). Within early endosomes, the acidic environment of the endosomal lumen releases hydrolases from the M6PR. After maturation into late endosomes a process that is accompanied by the generation of intraluminal vesicles via the endosomal sorting complexes required for transport (ESCRT) machinery (18) the late endosomes fuse with existing lysosomes, where hydrolases and other proteins like proteases accumulate and get activated to degrade proteins.

Another important pathway is the regulated secretory pathway. Specialized secretory cells such as endocrine, neuronal, exocrine, but also hematopoietic cells have the capacity of regulated secretion liberating secretory cargo stored in cytoplasmic granules following arrival of a stimulus (14). While endocrine, neuronal, and exocrine cells are known to form specialized SGs, cells from the hematopoietic lineage, but also some other cells such as melanocytes, possess mixed type organelles often called secretory lysosomes due to their close connection between the endocytic and exocytic pathway (19). They are characterized by the presence of lysosomal enzymes as well as markers of lysosomal origin such as CD63/LAMP-3, and LIMP IV/5G10 antigen (17). They often are also altered in patients with lysosomal storage diseases carrying mutations in a variety of genes involved in lysosome biogenesis (19).

The biogenesis of SG has been well worked out in neuroendocrine cells (15). In these cells, proteins targeted to the regulated secretory pathway become associated with specialized regions of the TGN forming larger aggregates that eventually associate with other soluble or membrane-localized cargo protein (sorting by entry) (14). After budding immature SG are formed that, via a series of homotypic fusion events, give rise to mature SG. This process is coupled to the removal of non-secretory missorted cargo via clathrin-coated vesicles (sorting by retention) and condensation, the latter being at least partially favored by the acidic environment in the granules maintained actively by proton pumps (5). In contrast to the well-characterized granule biogenesis in neuroendocrine cells, the biogenesis of secretory lysosomes is less clear. While melanosomes, for example, seem to derive from early or sorting endosomes with few small intraluminal vesicles (20), granules from lytic T cells are likely modified lysosomes containing a ring of multivesicular bodies, which derive from the fusion of late endosomes, surrounding a dense core that further matures upon $\mathrm{T}$ cell activation (19-21). The dense cores might derive, like for conventional SG, from the TGN. It is possible that proteoglycans may play an important role by their capacity to selectively aggregate and attract regulatory secretory proteins via charged interaction thereby serving as a nucleation point for sorting (22). In favor, experiments carried out with proteoglycan deficient hematopoietic cells, including MC, all show serious defects in granule biogenesis, protease content, and maturation (5). Additional studies showed that SG containing at least some of the granule proteases and mediators could still be formed even in the absence of proteoglycans leaving open the possibility of proteoglycan-independent formation of immature SG (23). However, the fact that all these SGs are morphologically altered lacking an electron dense core and crucial enzymes favor an important role of proteoglycans in physiological SG formation.

In MC, electron microscopy studies (24) have allowed to define three types of SGs: (1) type I SG likely representing matured endosomal/lysosomal organelles with numerous intraluminal vesicles that are rapidly accessible to endocytic tracers, (2) type II SG, which like in cytotoxic $\mathrm{T}$ cells contain a dense protein core surrounded by multivesicular bodies; these granules are also rapidly accessible to endocytic tracers, and (3) type III SG containing essentially electron dense material no more accessible to endocytic tracers. Likely, type III SGs are generated by a maturation process that may involve Synaptotagmin III (SytIII) regulating recycling and delivery of cargo to the endocytic recycling compartment (ERC) during granule maturation (25). This suggests that the ERC could be an important intermediate in granule recycling and maturation. The nature of the involved endocytic compartment is also not completely clear, but recent data have indicated an important role of the early endosomal marker Rab5 and VAMP-8 in granule size determination (26). This suggests that multivesicular bodies or type I SG may not derive from late endosomes but could directly form at the early endosome and fuse with Golgi-derived specialized SGs in homotypic fusion events (26). A possible role of SytIX in this process has been proposed as it excludes proteins destined for recycling to reach the SG (27). However, the fact that in human MC VAMP-7 serves as a soluble $N$-ethylmaleimidesensitive factor attachment protein receptor (SNARE) for release of SG may suggest that genuine late endosomes may also take part in the generation of SG (28). Granule maturation is a long process that can take several months in $\mathrm{MC}$, as indicated by data (29) showing that MC SG get gradually enriched with incoming cargo such as proteoglycans, MC proteases, but also histamine and serotonin, the latter of which being transported via vesicular monoamine transporter (VMAT) systems directly from the cytoplasm (5). Interestingly, these positively charged molecules also contribute to granule homeostasis as in their absence SG maturation is affected as shown for histamine and MC proteases (5, 30). In addition to these classical sorting pathways, the ERC, initially characterized for its role in the slow pathway of Transferrin recycling, has also gained attention as a new sorting hub actively sorting cytokines for release as demonstrated in macrophages (31).

\section{ANAPHYLACTIC DEGRANULATION PRESTORED INFLAMMATORY MEDIATORS}

$\mathrm{MC}$ are the effector cells of type I hypersensitivity reactions, which involves the release within a few minutes of cytoplasmic granular content into the surroundings after stimulation, a process often called anaphylactic degranulation (32). A potent stimulus for degranulation is the crosslinking of IgE bound to FceRI by 
multivalent antigens or allergens (3). Indeed, one distinctive features of MC is that they contain numerous SGs in their cytoplasm $(32,33)$. These granules are filled with different inflammatory compounds, many of which are bound to a highly charged anionic gel matrix composed of proteoglycans such as heparin or chondroitin sulfate, which differ among the different MC types and species (34). The presence of these proteoglycans attributes the specific staining properties of $\mathrm{MC}$ with cationic dyes such as toluidine blue enabling the classical metachromatic staining of MC in tissues, which have led to the discovery of these cells by Paul Ehrlich in the nineteenth century (35). Well-known mediators bound to these proteoglycans are cationic amines such as histamine or serotonin, but also proteases such as tryptase, chymase, and carboxypeptidase [for a complete review see for example (4, 36)]. The formation of such a gel matrix allows their tight packaging and is thermodynamically advantageous avoiding osmotic work (37).

When MCs are stimulated, up to $100 \%$ of granular content can be released in a single stimulation event within minutes enabling a maximal biological effect in its immediate vicinity, but also often with systemic effects as for example, occurring during a generalized anaphylactic shock $(38,39)$. This degranulation is made possible by a special type of exocytosis mechanism often called compound exocytosis involving the fusion of PM proximal granules with the PM followed by the sequential fusion with granules lying deeper in the cytoplasm (Figure 1). Although such sequential fusion events have been shown by electron microscopy studies (33), a multigranular fusion mode that leads to the fusion of large intracellular fused granules with the PM has often also been observed (40). Degranulation involves the extrusion of the whole condensed gel matrix, which is accompanied by a drastic swelling due to their hydration (41). The change in $\mathrm{pH}$ after release from the acidic milieu in the granule to the neutral $\mathrm{pH}$ in tissues allows the dissociation of cationic inflammatory mediators such as histamine and MC proteases (5). In addition to this anaphylactic degranulation mechanism, granular content can also be released in small portions by a mechanism called piecemeal degranulation (PMD), characterized by the gradual emptying of MC SG over much longer periods of time, but also kiss-and-run fusion involving only a short opening and contact with the external environment (see below).

While it was thought initially that cytokines are released only after new synthesis, in groundbreaking discoveries, Galli and coworkers (42) found that MC in addition to releasing newly synthesized TNF were able to store TNF in SG from where it could be released through anaphylactic degranulation. In particular, highly differentiated tissue $\mathrm{MC}$ such as peritoneal MC in mice were found to contain substantial amounts of TNF in their SG, while this was less the case in cultured cells. In fact, in some cultured MC lines, such as for example PT18 or RBL-2H3 $(42,43)$, no prestored TNF is detectable while this amount seems variable for other lines or primary cultured MC such as BMMC. Our own experiments in BMMC show that they contain detectable TNF that colocalizes with SG markers (Figure 2), but this concerns only a small fraction of cells, while other cells clearly express only classical granule markers such as serotonin or proteases. It is therefore possible that TNF can accumulate only in mature granules. As a possible mechanism a specific sorting signal based on $\mathrm{N}$-glycosylation

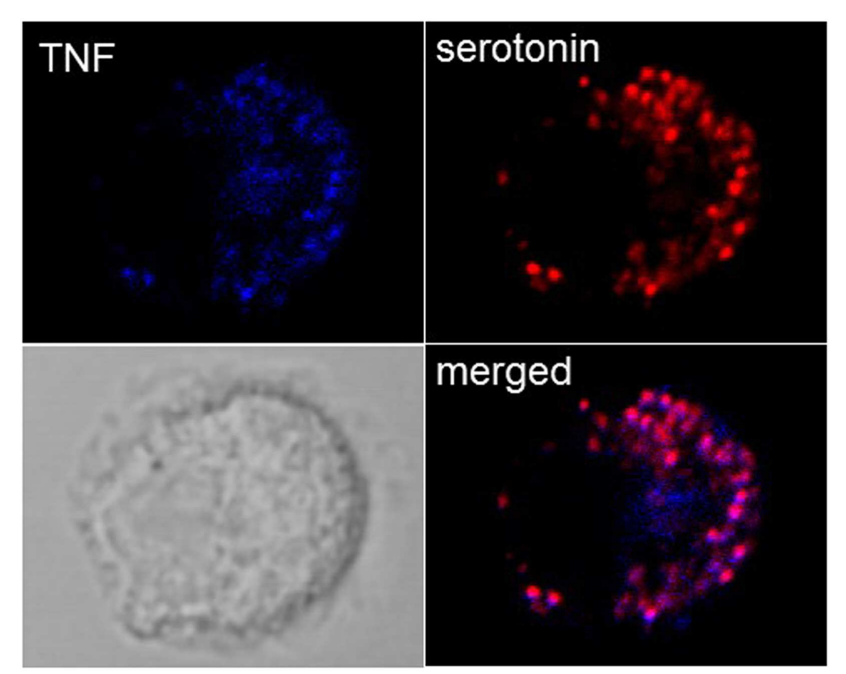

FIGURE 2 | Localization of TNF in SG in cultured BMMC. Colocalization of TNF (blue) with the SG markers serotonin (red) were analyzed in non-stimulated BMMC using confocal microscopy. Representative single optical sections and overlay (Merge) and the DIC images are shown. Note that in a single field only few cells show such TNF SG granular staining.

transporting TNF to the endosomal system was proposed (44). In human MC, where TNF is not glycosylated, TNF became enriched in SG after transient exposure on the PM and re-endocytosis (45). Besides TNF, a series of other cytokines including for example, IL4, IL-5, IL-13, and vascular endothelial growth factor (VEGF) have been reported to be prestored in MC SG (4). Prestored cytokines have also be found in other cells of hematopoietic origin including eosinophils, platelets, and neutrophils (46-49).

\section{EARLY SIGNALING PATHWAYS IN ANAPHYLACTIC DEGRANULATION}

Anaphylactic degranulation can be induced via immunoreceptors, the FceRI as a prototype (3), but MC can also be stimulated via IgG receptors under certain conditions (50). Furthermore, MCs express a whole variety of other receptors that can promote anaphylactic degranulation in particular certain $G$ protein coupled receptors (GPCRs) such as receptors for complement peptides $\mathrm{C} 5 \mathrm{a}$ and $\mathrm{C} 3 \mathrm{a}$, receptors for neuropeptides or receptor for certain inflammatory peptides such as for example endothelin (4). Independent of the receptor type, they all can induce a calcium signal and the activation of protein kinase $\mathrm{C}(\mathrm{PKC})$, in particular $\mathrm{PKC} \alpha / \beta$, which are necessary for anaphylactic degranulation to occur $(3,51)$. Signals which do not induce a substantial calcium response, such as for examples those generated via LPS and Toll-like receptors, although inducing the secretion of newly synthesized cytokines or chemokines do not induce anaphylactic degranulation.

Some recent reviews describe in detail the main molecular events following FceRI crosslinking in $\mathrm{MC}(6,51)$. Briefly, after antigen-dependent activation of FceRI receptor, Src family kinases Lyn and Fyn are activated causing phosphorylation of FceRI $\beta$ and FceRI $\gamma$ chains ITAMs (Figure 4). Receptor activation opens membrane calcium channels causing a receptor-operated calcium entry 


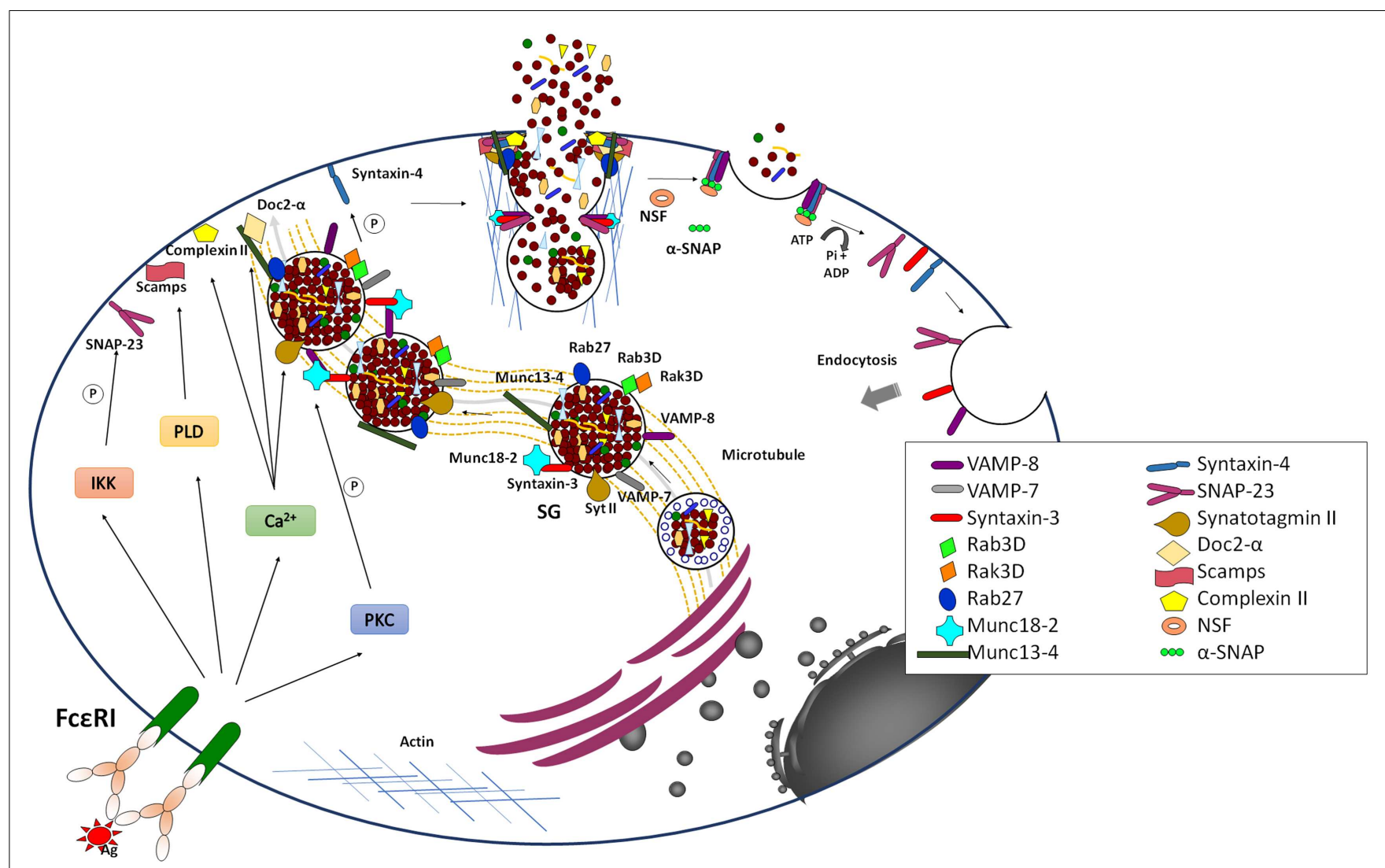

FIGURE 3 | Late signaling events in the anaphylactic degranulation. Aggregation of $\lg E$ bound to $\mathrm{F}_{\mathrm{C} \varepsilon \mathrm{RI}}$ leads to the generation of elevated levels of intracellular $\mathrm{Ca}^{2+}$ and the activation of PKC. In parallel, it also leads to the activation of PLD and IKB Kinase (IKK). Together they trigger anaphylactic degranulation, which involves SG-SG and SG-PM fusion events. Fusion is mediated by SNARE proteins that lie on opposing membrane. The formation of a stable well-characterized trans-SNARE complex in MC comprises the V-SNARES VAMP-8 that pairs with the two t-SNAREs, Syntaxin 4, and SNAP-23. During SG-SG fusion SNAP-23 relocates to the cytoplasm, which may be characteristic for the compound/multigranular fusion mode in $\mathrm{MC}$. The SG-localized t-SNARE Syntaxin 3 may be specifically implicated in SG-SG fusion events and in a manner opposite to SNAP-23 translocates to the PM upon activation. Other v-SNAREs like VAMP-2 and VAMP-7 might also play a role in anaphylactic degranulation, which may indicate redundance or heterogeneity of the MC secretory compartment. The formation of SNARE complexes is modulated by multiple accessories proteins such as Munc18-2, Synaptotagmin II, Complexin, SCAMP, Doc2 $\alpha$, Rab27A and B, and Munc13-4 that allow to connect the fusion machinery to early signaling events to relieve existing fusion clamps and to coordinate the docking, thethering, and fusion events as well as the connection to cytoskeletal reorganization and transport mechanisms. Fusion is closely coupled to endocytosis of membrane lipids and proteins. The individual SNARE proteins are reconstituted by an energy-requiring step, which is mediated by the NSF ATPase via the $\alpha$-SNAP adaptor protein.
(ROCE). Lyn kinase activation leads to the recruitment and activation of Syk kinase. Syk, in turn, phosphorylates the adapters LAT, SLP76, Gab2, and NTAL, among others. Those adapters participate in the assembly of large signaling complexes that include molecules such as Bruton's tyrosine kinase (BTK), which activates phospholipase $\mathrm{C} \gamma(\mathrm{PLC} \gamma)$ cooperatively with Syk. PLC $\gamma$ activation induces diacylglycerol (DAG) production and inositol-1,4,5-trisphosphate (InsP3)-induced $\mathrm{Ca}^{2+}$ mobilization. Emptiness of intracellular calcium stores leads to the activation of a store-activated calcium entry (SOCE) to replenish internal stores. DAG and $\mathrm{Ca}^{2+}$ induce the activation of classical isoforms of $\mathrm{PKC}, \mathrm{PKC} \alpha$, and $\beta$. On a complementary pathway, Fyn kinase phosphorylates Gab2 leading to the activation of phosphoinositide 3 kinase (PI3K). This results in activation of the PI3K-dependent protein kinase I (PDK1) and PKC $\delta$. PI3K activation induces Phospholipase D (PLD) and Akt activation, the latter favoring MC survival and $\mathrm{MTOR}$ activation $(51,52)$. The Lyn pathway is essential for $\mathrm{Ca}^{2+}$ signaling, whereas the Fyn-dependent pathway is required for degranulation and maintenance of $\mathrm{Ca}^{2+}$ mobilization (53).

\section{LATE SIGNALING EVENTS IN ANAPHYLACTIC DEGRANULATION}

In addition to calcium and PKC, many different actors that are involved in the control of fusion during degranulation have been recently described (Figure 3 ). These include the highly conserved SNARE membrane fusion proteins (54-57). SNAREs can be divided into vesicular (v-SNARE) and target ( $t$-SNAREs) localized, respectively, on opposing donor and acceptor membranes. They contain in their primary structure and about 60 aa $\alpha$-helical SNARE motif, which upon arrival of the appropriate stimulus, can zipper to form a tight tetrameric trans-SNARE complex (composed of one v-SNARE and either two or three t-SNAREs, depending on the number of contained SNARE motifs) that drives the merger of lipid bilayers. After fusion SNAREs are disassembled under 
energy consumption by the ATPase $N$-ethylmaleimide-sensitive factor (NSF), which becomes recruited to the SNARE complex via an adaptor called Soluble NSF Attachment Protein (SNAP).

While, SNARE complex formation and fusion can be reconstituted into liposomes in the absence of any additional protein (58), the process is extremely slow indicating additional control mechanisms. In living cells, numerous accessory proteins have been found to regulate membrane fusion including Sec1/Munc18 (SM), Munc13-, Rab-, complexin-, and Synaptotagmin (Syt)-family members $(56,59)$. Together, they are responsible for the priming, tethering, and docking to ensure specificity and efficiency of the fusion process. They also allow to connect the fusion machinery to cell stimulation relieving existing fusion clamps. Many were initially characterized in neuronal secretion at the synapse. Although, in general, the basic principles described may apply to secretion in other cells, differences clearly exist. In particular, vesicular release at the synapse is set up for an extremely fast (within milliseconds) release followed by a fast recycling process at specific active zones requiring likely additional proteins such as voltage-gated calcium channels or proteins involved in vesicle docking such as RIM (59). In other cells, such as MC the process is generally more dynamic and might require a more extensive crosstalk with the cytoskeleton for transport mechanisms that does not occur at specific active zones. Furthermore, as mentioned above, they involve also granule-granule fusion events to obtain a maximal release within the scale of a few minutes. Some of the differences are summarized in Table 1.

Several of the early studies in MC provided convincing evidence that, like in neurons, fusion implies SNARE proteins (60-63).

Table 1 | Comparison of exocytosis in mast cells and neurons.

\begin{tabular}{|c|c|c|}
\hline Parameter & Mast cells & Neurons \\
\hline Granules & Secretory lysosomes & $\begin{array}{l}\text { Specialized secretory } \\
\text { granules }\end{array}$ \\
\hline Granule size & 300-1000 nm & $50 \mathrm{~nm}$ \\
\hline Granule number & Up to $1000 /$ cell & 200-500/nerve terminal \\
\hline $\mathrm{Ca}^{2+}$ requirements & $1 \mu \mathrm{M}$ & $200 \mu \mathrm{M}$ \\
\hline PKC requirement & Yes & No \\
\hline $\begin{array}{l}\text { Time frame of } \\
\text { exocytosis }\end{array}$ & Minutes & Milliseconds \\
\hline Recycling time & Long (hours to days) & $\begin{array}{l}\text { Very short (seconds to } \\
\text { minutes) }\end{array}$ \\
\hline Site of release & Multidirectional $^{a}$ & Active zone \\
\hline $\begin{array}{l}\text { Release } \\
\text { characteristics }\end{array}$ & $\begin{array}{l}\text { One single release, up } \\
\text { to } 100 \% \text { of total } \\
\text { granular content; multi- } \\
\text { granular/compound } \\
\text { mode }\end{array}$ & $\begin{array}{l}\text { Multiple release one } \\
\text { granule per fusion event }\end{array}$ \\
\hline
\end{tabular}

${ }^{a}$ Note that under specific local conditions of stimulation, mast cells are able to deliver SG content within specific zones.
Work from several laboratories has allowed to define a central SNARE complex composed of the PM-localized t-SNAREs SNAP-23 and Syntaxin 4 as well as the vesicular localized VAMP-8 (64-66). Interestingly, SNAP-23 was found to relocate to the cytoplasm in degranulation channels following activation, which could be a specific characteristic of the compound/multigranular mode of fusion as it enables granule lying deeper inside to get access to this PM SNARE (60). Furthermore, the implication of VAMP8 , which was initially described as an endosomal SNARE called endobrevin (67) was a clear indication for the close connection of the granular compartment with the endosomal/lysosomal system. In addition to these three SNAREs other possible SNAREs implicated include Syntaxin 3, VAMP-7, and VAMP-2 (28, 66, 68-70). In murine, but not in human MC (71), Syntaxin 3 is localized to SG and translocates to the $\mathrm{PM}$, which might in a manner analogous to SNAP-23 be a characteristics of the compound/multigranular mode of fusion (70). However, the association with other SNARE proteins like Vtilb involved in vesicular fusion events is also possible (55). The fact that several types of SNARE complexes are implicated in membrane fusion in MC could be in agreement with the heterogeneity of the secretory compartment.

In addition to cognate SNARE proteins anaphylactic degranulation is regulated by an array of additional factors and signaling events. They include small GTPases known to regulate and coordinate discrete steps along the vesicular trafficking (72). A functional screen comprising 44 different Rab GTPases showed that many Rabs can affect either antigen and/or ionomycin/PMA triggered anaphylactic degranulation (73). The best characterized Rabs are the Rab27A and B isoforms. These studies indicate that while Rab27A may play a role in regulating the cortical actin disassembly limiting access of SG to the membrane, the role of Rab27B or the combined action of Rab27A and B facilitates degranulation by switching granules from microtubule-dependent movement to F-actin-dependent docking $(74,75)$. Indeed, degranulation is also accompanied by important remodeling of the actin cytoskeleton, which may favor the access to the PM (3). The docking step may imply another important factor, Munc13-4, that interacts with Rab27. Indeed, it was shown in MC that the interaction between both partners was required to correctly tether SGs at the PM and to prime them for fusion (75-77). Controversial data have been obtained with regard to the role of Rab3 isoforms. While initial data showed a potential role of Rab3A (78), we found that this isoform was not targeted to membranes in RBL MC and that its overexpression had no effect $(79,80)$. Rab3D, on the contrary, was SG-localized (81). Overexpression of wild-type and a constitutively active Rab3D mutant affected exocytosis (79). However, this was not confirmed in MC obtained from Rab3D knock-out animals although compensatory mechanisms by other Rab3 isoforms have not been examined (82).

Sec1/Munc18 protein family members are another type of fusion accessory proteins. They include three Munc18 isoforms implicated in exocytosis and some other family members involved in intracellular trafficking steps (56). Initial analysis of the neuronal isoform Munc18-1 suggested that it might be a negative regulator of fusion by its capacity to bind to particular syntaxin SNAREs preventing the binding of cognate SNARE partners. However, analysis of knock-out mice showed that its absence 
completely blunted synaptic transmission advocating a positive regulatory function (56). Later on this was explained functionally by data showing that during exocytosis Munc18-1 switches its binding mode to bind the assembled SNARE complex thereby aiding the fusion process probably by electrostatic interactions with the membrane for fusion pore expansion $(56,83,84)$. MC do not express protein of the neuronal isoform Munc18-1 but express ubiquitious Munc18-2 and Munc18-3 (85, 86) and Munc18-1 does not seem to play a role (87). No functional data have been obtained for Munc18-3, but several studies by different authors have clearly shown that the Syntaxin 3 binding protein Munc18-2 acts as a positive regulator of fusion as in its absence exocytosis is compromised in MC $(70,88,89)$ but also in other hematopoietic cells (90). Further functional studies indicated that knock-down of both Syntaxin 3 and Munc18-2 yielded additive inhibitory effects on exocytosis suggesting that Munc18-2 besides fusion might regulate additional steps (70). Video imaging of SG movement indicated that Munc18-2 affected SG translocation to the membrane, likely through its dynamic interactions with the microtubule cytoskeleton (70). Munc18-2 may also represent a possible target for the action of protein PKC $(8,91)$. As data in chromaffin cells already suggested a docking effect (92), it may be possible that SG docking may not be static, but rather a dynamic process that needs to be maintained via cytoskeletal interactions. In agreement, the neuronal Munc18-1 isoform has also be found to bind to the Kinesin-1 adaptor protein, fasciculation, and elongation protein zeta-1 (FEZ1) (93).

Secretory carrier membrane proteins (SCAMPs), a family of ubiquitous membrane proteins of transport vesicles (94) has also been shown to regulate fusion. These tetraspanins contain a short conserved segment (E-peptide) between the second and third transmembrane domain. MCs express three SCAMP isoforms, with SCAMP1 and SCAMP2 being most highly expressed. Introduction of the E-peptide interfered with degranulation in permeabilized MC $(95,96)$. SCAMPs may act at the final fusion step in agreement with data showing that genetic deficiency of SCAMP2 causes an apparent defect in forming stable fusion pores that may depend on Arf6-stimulated PLD activity (94). PLD was indeed proposed as an effector in MC exocytosis (97).

Several effectors molecules have been described that connect the fusion apparatus to $\mathrm{Ca}^{2+}$ signaling. This includes Syt family proteins, which are single transmembrane proteins with tandem calcium-binding C2 domains (termed C2A and C2B). Calciumbinding promotes oligomerization and membrane phospholipidbinding as well as the interaction with the SNARE complex, allowing the formation of a quaternary SNARE-Syt-Ca ${ }^{2+}$-phospholipid (SSCAP) complex driving of lipid bilayer mixing (98). While, neuronal expressed SytI was initially characterized as a possible sensor (99), recent studies in knock-out mice provided a clear evidence for the role of SG-localized SytII as the relevant $\mathrm{Ca}^{2+}$ sensor in MC (100). MC deficient in SytII showed a severe defect in both lysosomal $\beta$-hexosaminidase and histamine release and conferred to these mice a strongly decreased passive cutaneous anaphylaxis reaction (100). Although in addition to SytII, other Syt isoforms are expressed in MC, they do not seem to be directly involved in the fusion process but rather may regulate other intracellular trafficking steps (7). SytII may act in concert with ComplexinII $(101,102)$, a protein that binds to assembled SNARE complexes and that has been described in neurons to function as a fusion clamp. However, data from knock-out mice also support a positive action on exocytosis involving sequences adjacent to the SNARE-complex-binding domain. It seems that its interaction with the SNARE complex generates a metastable state that serves as a substrate for Syt following $\mathrm{Ca}^{2+}$-influx with the induced rearrangement and cooperative interactions promoting fusion $(56,59)$.

In addition to Syt, Doc2 adaptors also contain tandem calciumbinding $\mathrm{C} 2 \mathrm{~A}$ and $\mathrm{C} 2 \mathrm{~B}$ domains the former of which exhibiting calcium-dependent phospholipid-binding activity thought to be important for regulated exocytosis through possible interactions with Munc13 isoforms as well as partly assembled SNARE complexes (103). MCs express the Doc $2 \alpha$ isoform thought to be neuronal-specific, while the ubiquitous $\operatorname{Doc} 2 \beta$ isoform was not expressed (104). Doc $2 \alpha$-deficient MC showed a marked defect in degranulation and formed a tripartite complex with Munc13-4 and Rab27 suggesting that it could play a role in vesicle priming (104). Another possible $\mathrm{Ca}^{2+}$-dependent process involves a kinase activity called Rak3D (from Rab3D-associated kinase) that was associated with Rab3D (105). Rak3D phosphorylated Syntaxin 4, but not Syntaxin 2 and 3 in its N-terminus, which prevented binding of the SNARE partner SNAP-23 suggesting that it could act as a fusion block. In agreement, the association with Rab3D decreased upon stimulation in a calcium-dependent manner. While phosphorylation of Syntaxin 4 was fusion inhibiting, phosphorylation of the other t-SNARE protein SNAP-23 rather seemed to be fusion promoting. This involved IКB kinase (IKK) also known to regulate the phosphorylation of $\mathrm{I} \kappa \mathrm{B}$, which induces nuclear translocation of the NF- $\kappa$ B transcription factor (106). Indeed, in activated MC IKK phosphorylated a small fraction $(\sim 10 \%)$ of SNAP-23 on Ser95/Ser120 within its cysteine-rich linker region. In the absence of IKK, degranulation and anaphylactic responses were impaired. This was associated with decreased SNARE complex formation indicating a role for SNAP-23 phosphorylation in fusion.

\section{OTHER FORMS OF DEGRANULATION PIECEMEAL DEGRANULATION}

Piecemeal degranulation is a mode of exocytosis characterized by loss of granule content in the absence of clearly observable granule-granule or granule-PM fusion events. PM is associated with the generation of small vesicles ranging from 30 to $150 \mathrm{~nm}$ budding from large SGs $(107,108)$ (Figure 1). Empty spaces of lost secretory particles are recognizable inside the SG, without evidence for changes in the size of the granule membrane. The mechanism behind PMD is known as the "shuttling vesicle" hypothesis (109). According to this, the transport of granule constituents out the cell is mediated by vesicles shuttling from the granule compartment to the PM. Electronic microscopy has shown, in fact, that vesicular transport granule content is associated with this type of secretion (110). Thus, an outwarding flow of cytoplasmic vesicles loaded with granule materials effects granule depletion during PMD. Vesicles containing part of the granule content buds from the granule membrane and move through the cytoplasm and fuse with the PM, leading to content discharge. In a closely coupled inward flow, endocytotic vesicles are retrieved from the PM and traverse the cytoplasm to fuse with granules. If the rate and amount 
of vesicular traffic are balanced, granules and PM will maintain constant size. The most important characteristic of PMD is the fact that it seems to be modulated in different steps and by different stimulants. Strongly enhanced PMD was observed in mice overexpressing IL-4 resulting in eyelid lesions and enhanced fibrosis (111) or in human MC after stimulation with IL-1 (112). PMD has been studied in a number of different immune cells (47) but also enteroendocrine cells of the gastrointestinal tract, chromaffin cells of the adrenal medulla and chief cells of the parathyroid gland (108).

Alternatively to the shuttling vesicle hypothesis, PMD could also be the results of kiss-and-run fusion, which also result in partial vesicle emptying (see below).

\section{KISS-AND-RUN EXOCYTOSIS}

Kiss-and-run exocytosis refers to a special type of secretion in which a fusion pore opens and closes during vesicle fusion with the PM, allowing the release of some amount of granule content without full vesicle collapse (113). Kiss-and-run exocytosis (also known as "cavicapture") has been reported in PC12 cells (114), chromaffin cells (115), and insulin secreting pancreatic beta-cells (MIN6)-cells (116). In MC, initial classical patch clamp studies led to the observation of capacitance changes in the PM due to exocytosis of individual granule contents after GTP addition and, interestingly, this event seemed to be independent of $\mathrm{Ca}^{2+}$ mobilization (117). Later, a series of experiments using peritoneal MC from beige mice demonstrated "capacitance flickering" after intracellular administration of GTP $\gamma \mathrm{S}$, suggesting rapid and reversible steps in membrane fusion due to the opening and closing of a fusion pore, narrow enough to retard the escape of some molecules (118) but leading to the leakage of some soluble granule components. Besides these electrophysiological measurements kiss-and-run fusion in MC could also be observed directly in multicolor multiphoton fluorescence microscopy in histamine loaded cells through the $\mathrm{pH}$ cycling that occurs after a release event. In these studies using a tumor MC line the authors found that kiss-and-run fusion occurs actually very frequently accounting for about one-third of all fusion events in MC (119).

The choice between kiss-and-run and full fusion of vesicles may depend on several different mechanisms. One vision is that kiss-and-run fusion occurs when the threshold for full fusion is not reached. The threshold would be determined by the interplay between the regenerative recruitment of SNARE-mediated force and some kind of restraining force that counterbalance vesicle fusion. According to this "restraining force hypothesis" cytoskeleton-dependent restraining barriers exist that counterbalance SNARE-driven fusion mechanisms (113). Studies in neurons have shown that the relative incidence of kiss-and-run fusion is strongly regulated by key factors such as intracellular calcium accumulation, impulse frequency, and a previous history of activity. Calcium is important to switch the kiss-and-run mode of secretion to the full fusion events. High calcium shifts the mechanism from kiss-and-run to complete fusion (120). Furthermore, some lines of evidence suggest that the number of SNARE complexes might also be important in the balance between kiss-and-run and full fusion. In reconstituted systems (121), it has been calculated, for example, that one SNARE complex is sufficient for the bilayer fusion observed in kiss-and-run and three of those complexes are needed to prevent the nascent fusion pore from reclosing (a phenomenon needed in full fusion exocytosis). Also, the stability of the fusion pore can be altered by accessory proteins of SNARE function, including Syt (122), complexin (123), and G $\beta \gamma$ (124).

\section{ENDOCYTOSIS-EXOCYTOSIS COUPLING}

Regardless of the mechanism of exocytosis, the incorporation of membrane during exocytosis has to be closely coupled to endocytosis to retrieve the additionally inserted membrane. Several modes of endocytosis have been characterized (125). They include endocytosis after (i) full-collapse fusion, in which collapsed vesicles are retrieved by classical endocytosis involving membrane invagination and vesicle reformation, (ii) kiss-and-run fusion, in which the fusion pore just opens and closes without any significant membrane traffic, and (iii) after compound/multivesicular exocytosis one can also observe bulk endocytosis that retrieves giant vesicles from the membrane. In agreement with the multiple types of exocytosis in MC, a recent electrophysiological study has shown that, in addition to classical mode endocytosis, kiss-and-run as well as compound exocytosis events can be delineated (126).

Following exocytotic fusion the formed SNARE complexes are also reconstituted into the individual SNARE proteins. This is achieved by the NSF ATPase (127) and represents the energy consuming step within the SNARE cycle (98). The necessity of NSF in MC exocytotic event has been demonstrated by the fact that transfection of an inactive NSF mutant into RBL MC blocks degranulation (63).

\section{DE NOVO SECRETORY PATHWAYS}

Besides secreting mediators prestored in cytoplasmic granules, MC release also a whole array of de novo synthesized mediators. These include lipid compounds such as leukotrienes and prostaglandins, which are generated from arachidonic acid released from nuclear membrane phospholipids through the action of cytosolic phospholipase A2. These compounds are synthesized in the cytosol and then diffuse across the PM due to their lipid-derived nature and hence do not require lipid transport mechanisms (128).

MC also synthesize and release a large set of different cytokines, growth factors, and chemokines. An extensive list produced by MC can be found in a review by Galli and coworkers (4). Contrary to the lipid mediators, they are proteins and synthesized at the rough ER and released along the secretory pathway using vesicular carriers (31). As indicated certain cytokines and growth factors such as TNF and VEGF have also been shown to be present in cytoplasmic granules and thus can also be released by anaphylactic degranulation providing an immediate source available within minutes $(4,42)$. On the contrary de novo synthesized cytokines and chemokines require several hours to obtain maximal levels of secretion engaging complex signaling pathways. They involve transcriptional regulation through transcription factors, epigenetic control mechanisms, as well as post-transcriptional regulation through mRNA stabilization and microRNA (miRNA). Signaling pathways also exist at the level of vesicular trafficking regulating the selective sorting to specific small vesicles and tubovesicular organelles. The relative contribution of these control mechanisms 


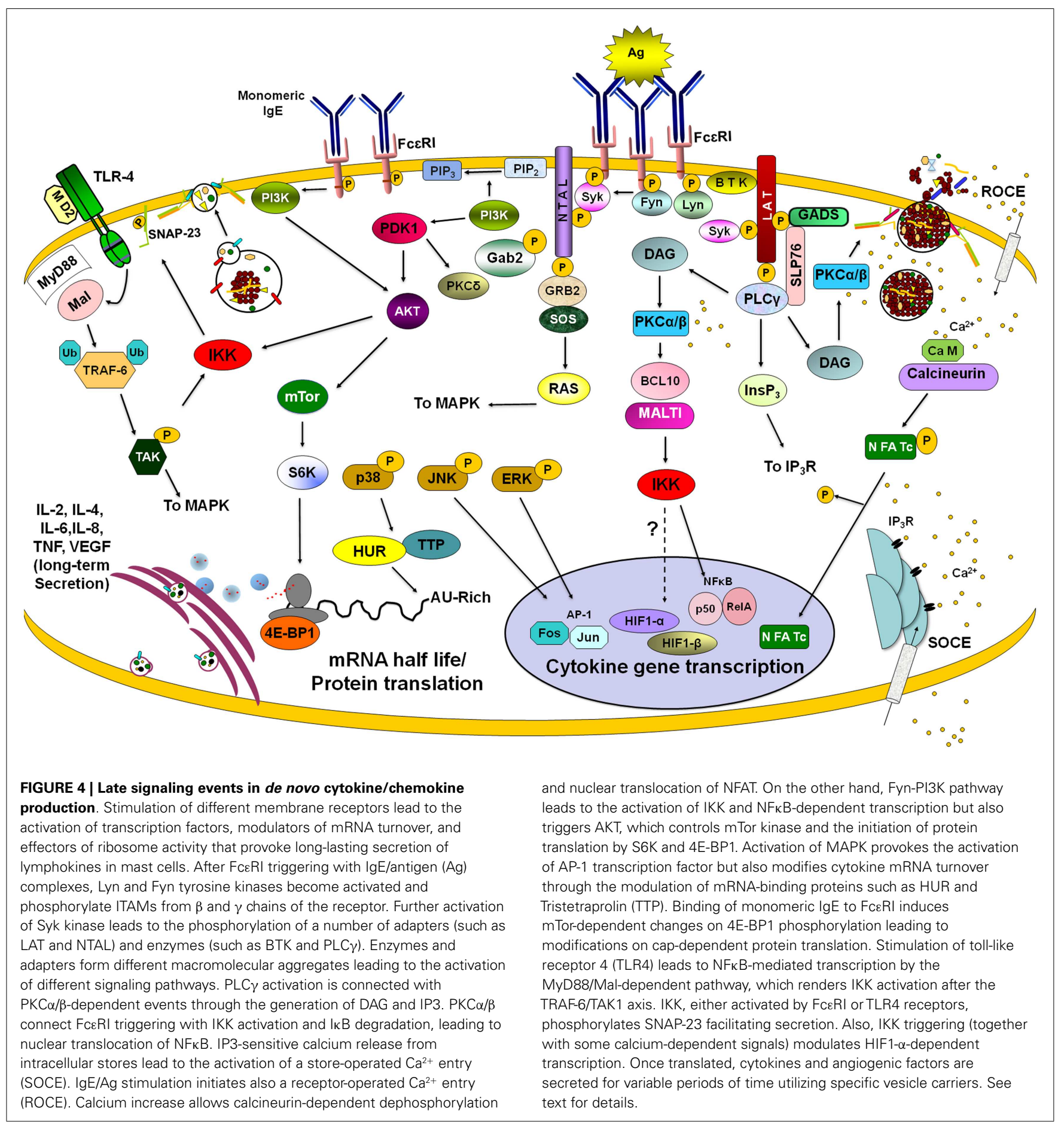

remains to be clarified but could largely differ between individual cytokines and chemokines. Some of the important signaling steps leading to their secretion are summarized in the following chapters.

\section{TRANSCRIPTIONAL CONTROL BY THE ACTIVATION OF TRANSCRIPTION FACTORS}

Figure 4 displays some of the important signaling pathways controlling de novo synthesis of cytokines in MC. Some of the details of the early signaling events leading to the activation of $\mathrm{Ca}^{2+}$ mobilization and PKC via PLC $\gamma$ and DAG have already been described above. This PLC $\gamma$-DAG-Ca ${ }^{2+}$ signaling then initiates a signaling wave that culminates in the activation of different transcription factors for cytokine/chemokine production. Important transcription factors include nuclear factor of activated $\mathrm{T}$ cells (NFAT), nuclear factor-kappa B (NFk-B), and activator protein-1 (AP-1), but many other transcription factors may also be involved depending on the cytokine/chemokine gene. 
Nuclear factor of activated $\mathrm{T}$ cells are a family of four transcription factors (NFAT1-4) that in normal conditions are phosphorylated and reside in the cytoplasm (129). MCs have been shown to express NFAT1 and 2 (130). In stimulated cells, NFAT becomes dephosphorylated by calcineurin, a $\mathrm{Ca}^{2+}$-calmodulindependent serine/threonine phosphatase. This results in a conformational change that now exposes a nuclear localization sequence (NLS), which binds importins, allowing NFAT translocation to the nucleus and initiation of the transcription of a number of proinflammatory and regulatory cytokine genes, such as IL-2, IL-4, IL-13, and TNF $(130,131)$. The rephosphorylation of NFAT then exposes a nuclear export sequence (NES) enabling transport back into the cytosol via the exportin Crm1.

Another essential transcription factor regulating cytokine expression in MC is NFKB (132). This family of proteins includes

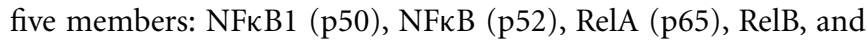
cRel. Although they can form different homo and heterodimers, $\mathrm{p} 50 / \mathrm{cRel}$ is the most common form of NFкB in immune cells (133). In MC, as in other immune cells, the activity of NFKB is controlled by inhibitor of kappa B (IкB) protein that binds to the heterodimer in the cytoplasm maintaining it in an inactive conformation. Activation of NFKB occurs when the IKK phosphorylates I $\kappa$ B on serine residues to target it to proteasomal degradation after polyubiquitination (133). FceRI-dependent activation of NFкB in MC depends on the activation and lipid raft recruitment of the classical isoform of PKC $\beta$ (134) and on the formation of a complex formed by B cell lymphoma 10 (Bcl10) and mucosal-associated lymphoid tissue 1 (Malt1) (135). The PKC $\beta-B c l 10-M a l t 1$ complex is necessary for NFKB activation and cytokine gene transcription, but not for secretion of pre-formed mediators in MC. Bcl10- and Malt1-deficient MC show normal MAPK (p38, ERK, and JNK), PKC and Akt activation after FceRI crosslinking but IKK-induced phosphorylation of I $\mathrm{B} \alpha$ and its degradation is completely blocked (135). NFkB is essential for the synthesis of an important number of cytokines in MC including TNF and IL-6 (136).

Besides binding PKC DAG also binds to RAS-guanyl nucleotide-releasing protein (Ras-GRP). Together they activate MAPK and IKK, leading to the activation of the AP-1 (Fos-Jun) and nuclear factor $\kappa \mathrm{B}(\mathrm{NF \kappa} \mathrm{B})$ transcription factors, respectively $(137,138)$. AP-1 consists of homo- and hetero-dimers of Jun family proteins, as well as heterodimers of Fos an Jun (139). Fos and Jun proteins are also synthesized and activated by phosphorylation (140). AP-1 acts together with NFAT and NFKB for synergistic activation of cytokine genes (129) for example after costimulation of MC with antigen and IL-33 (141).

Interestingly, NFAT, AP-1, and NFאB are optimally activated in response to different patterns of $\mathrm{Ca}^{2+}$ signaling in $\mathrm{T}$ cells. Transient high $\mathrm{Ca}^{2+}$ spikes lead to sustained activation of JNK and NFKB, but not NFAT, whereas, prolonged low increases in $\left[\mathrm{Ca}^{2+}\right] \mathrm{i}$, were sufficient to activate NFAT (142). Furthermore, as already mentioned above release characteristics depends on the strength of stimulus and this also holds true the activation of NFAT in MC (143).

\section{POST-TRANSCRIPTIONAL CONTROL OF CYTOKINE PRODUCTION}

Post-transcriptional regulatory mechanisms play an important role in the regulation of cytokine gene expression (144). They depend in part on specific mRNA sequences present in the $3^{\prime}$ untranslated region ( $3^{\prime}$ UTR). One major class consists of a conserved AU-rich sequence element (ARE) composed of several repeats of the pentanucleotide AUUUA present in mRNAs encoding growth factors, oncoproteins, or cytokines (145). The ARE has been associated with both an accelerated degradation of mRNA and interference with translation (146). Investigations in mice lacking the TNF ARE sequence in the mouse genome have clearly shown that the TNF ARE was required both for the alleviation and reinforcement of message destabilization and translational silencing in stimulated cells. Moreover, the mutant mRNA was no longer responsive to translational modulation by p38 and JNK kinases, demonstrating that the TNF ARE is a target for these signals (147). One major regulator in this mechanism is TTP, the prototype of a $\mathrm{CCCH}$-zinc finger proteins able to bind to the ARE and to interact with a number of proteins able to regulate mRNA stability and translational control (148). In unstimulated cells, TTP associates with factors that mediate translational repression and mRNA decay, while in stimulated cells with high p38-mitogen-activated protein kinase (p38) and the c-Jun N-terminal/stress-activated protein kinase (JNK/SAPK) activity it associates with proteins that enhance mRNA stability and translation (148).

Cytokine synthesis is also controlled at the level of translation initiation (149). The key signaling pathway controlling the initiation of translation in eukaryotic cells has been shown to be commanded by the mTOR kinase (150) related to lipid kinases and an essential component of two distinct multiprotein complexes named mTOR complex 1 (mTORC1) and mTOR complex 2 (mTORC2) (150). mTORC1, the rapamycin-sensitive complex, consists of mTOR, raptor, and LST8. The mTORC1 signals to inhibitory 4E-binding protein-1 (4EBP-1) and 40S ribosomal protein S6 kinase (S6K), which mediates efficient cap-dependent translation initiation (151). PI3K regulates the mTORC1 pathway via the activation of AKT (151). In MC, IgE-Ag stimulation induces PI3K-dependent activation of mTORC1, S6K1, and 4EBP1 (52). Inhibition of mTORC1 with rapamycin had no effect on degranulation but inhibited IgE/Antigen-induced IL-6 and IL-8 production and MC survival (52). Interestingly, rapamycin also provoked the destabilization of TNF $\mathrm{mRNA}$ in a process that required the TNF ARE in RBL-2H3 cells (152).

Besides cap-dependent translation, mRNAs for some angiogenic mediators, such as the VEGF, can be translated from a structured RNA element termed an internal ribosomal entry site (IRES) able to recruit the $40 \mathrm{~S}$ ribosomal subunit (153). It has been found that in response to hypoxia and some other stimuli, 4E-BP1 and eIF4G participate in a regulatory pathway that switch protein translation from the normal cap-dependent to the IRES-dependent process (154) allowing selective protein synthesis to cope with an adverse environment. In MC, monomeric IgE induces the release of VEGF from a pre-formed pool but also importantly induces the production of VEGF mRNA by the longlasting secretion of newly synthesized protein (155). IgE addition to BMMCs leads to dephosphorylation of $4 \mathrm{E}-\mathrm{BP} 1$, indicating that low-level stimulation of FceRI is able to induce IRES-dependent translation. The translational switch triggered by IgE was dependent on Fyn kinase activation and correlated with an increase in VEGF mRNA accumulation and VEGF secretion (156). 


\section{microRNAs AND CYTOKINE PRODUCTION IN MC}

microRNAs are a large class of endogenous single-stranded small non-coding RNA molecules that control gene expression by binding to the $3^{\prime}$ untranslated region ( $3^{\prime}$ UTR) of mRNAs thereby reducing protein synthesis through repression of translation or induction of mRNA degradation. miRNAs control maturation, proliferation, migration, and activation of immune cells (157). MCs express a number of different miRNAs implicated in production of pro-inflammatory mediators. For example, miR-221, originally described to regulate the cell cycle of MC, was shown to favor $\mathrm{MC}$ adhesion and migration toward SCF or antigen. This improved IgE/Ag-mediated degranulation and IL-6 and TNF production (158). The miR-146a was found to negatively regulate $\mathrm{NF} \kappa \mathrm{B}$ signaling, blunting the elevated cytokine production after bacterial infections (159) and contributing to endotoxin tolerance. In MC, miR-146a expression in response to different stimuli is dependent on NFKB p50 (160). MiR-155 expression enhanced FceRI degranulation and release of TNF, IL-6, and IL-13 related to the activity of the PI3K/Akt pathway (161). Recently, a systematic analysis of miRNA expression during the differentiation of BMMCs lead to the identification of 11 miRNAs that regulate the expression of specific transcription factors and 13 miRNAs that target transcripts of $\mathrm{mMCP} 4$ and $\mathrm{mMCP} 6$, regulating the synthesis of pre-formed inflammatory mediators (162).

\section{EPIGENETIC CONTROL OF CYTOKINE PRODUCTION IN MC}

Epigenetic modifications have been shown to influence the synthesis of transcription factors and to modify the sensitivity of promoters including in MC (163). For example, in vitro MC differentiation of $\mathrm{MC}$ was associated with decreased CD34 expression and increased HIF1A expression compared with bone marrow precursors. These changes were paralleled with changes in the methylation status of the promoters of those genes, suggesting that DNA methylation-dependent epigenetic regulation mediates the gene expression changes involved in maintaining the phenotype of mature MCs together with the differentiation of the HMC-1 cell line $(164,165)$. In another study, two constitutively DNAse I hypersensitivity sites (HSs) were described within the first intron of the IL-13 gene present in MC regulating the accessibility of the IL-13 locus for high level transcription (166). In the murine MC line derived from fetal liver CFTL-15, a cis-acting element in the second intron of the murine IL- 4 gene has a dual function in regulating transcription in $\mathrm{MC}$ as well as chromatin accessibility of the IL-4 gene locus through the influence on the methylation state of the gene. MC-restricted transcription factors GATA-1/2 and PU.1 associate with the intron element and regulate its activity $(167,168)$.

Epigentic modifications are involved not only in the increase on gene transcription but also in the long-term inhibition of cytokine synthesis. In the THP-1 promonocytic cell line, during endotoxin tolerance, it was found that transcription of TNF gene in normal cells was preceded by dissociation of heterochromatin-binding protein $1 \alpha$, demethylation of nucleosomal histone $\mathrm{H} 3$ lysine 9 increased phosphorylation of the adjacent serine 10 , and recruitment of NFKB RelA/p65 to the TNF gene promoter. This was no more observed in tolerant cells and RelB, a repressor of transcription, remained bound to the promoter during silencing (169).
Since MCs become tolerant after prolonged exposure to LPS, it is possible to speculate that the mentioned mechanisms of TNF gene silencing could also apply.

\section{MOLECULAR TRAFFICKING EVENTS IN CYTOKINE/CHEMOKINE SECRETION}

Contrary to the considerable advances made in the understanding of the regulation of fusion during anaphylactic degranulation, little is still known about the vesicular trafficking involved in MC cytokine/chemokine secretion. One problem is that endogenous cytokines and chemokines are not easily traceable for imaging studies due to the fact that they are secreted over a period of several hours. Thus, for example in macrophages one can observe protein accumulating in the Golgi, while vesicular structures are more difficult to delineate (170). Yet, Stow and coworkers have succeeded to image TNF secretory vesicles in macrophages, which produce considerable amounts of TNF that can be further enhanced by costimulating cells with IFN $\gamma$ (171). Furthermore, in the case of TNF, addition of a TNF converting enzyme (TACE) inhibitor allows to block cleavage of transmembrane TNF at the PM and to detect its accumulation in the cell surface or in endocytosed vesicular structures (172). In some cases, the authors have also used overexpressed fluorescently tagged cytokines (TNF or IL-6) (173). Interestingly, while continuously produced from the viral promoter, their protein expression further increases after stimulation, which may in part be due to the fact that stimulation leads to enhancement of posttranslational control and vesicular trafficking mechanisms.

Accumulated data suggest that chemokine/cytokine secretion does not follow a unique trafficking pathway but rather could involve multiple pathways and organelles depending also whether they get delivered locally, such as for example at the T cell synapse (174) or the phagocytic cup in macrophages (31) or whether the release is more multidirectional on the cell surface. However, all studies agree that cytokine trafficking differs from the secretion of cytoplasmic SGs containing prestored mediators such as for example shown in NK cells (175).

Most of the vesicular trafficking events have been studied in macrophages. Here, after the initial transport through the Golgi stacks, TNF and IL-6 were found to bud off in highly dynamic tubular-vesicular structures (173). Interestingly, while TNF was generally found together with IL-6, the majority of IL- 6 was found in independent carriers. All of them were finally delivered to the ERC, but they seem to reside in distinct non-overlapping areas. From the ERC, the individual cytokines are secreted independently with TNF largely fusing locally at the phagocytic cup, while IL-6 is secreted independently and not targeted to the phagocytic cup. This suggests that the ERC acts as a sorting hub for local secretion of cytokines. Interestingly, examination of another cytokine, IL10 , shows that only about half is delivered to the ERC, while the other half takes another transport route where it is directly delivered from the TGN to the PM via vesicular carriers containing the lipid binding protein ApoE (176). PMD has also been evoked as another mechanism for cytokine secretion. This concerns mostly cytokines prestored in cytoplasmic granules of eosinophils (177).

Concerning the SNARE fusion proteins necessary for constitutive secretion it was found that stimulation of macrophages 
generally increases their expression, which could be a means to enhance the cytokine trafficking $(171,178)$. Similarly, some other regulatory proteins such as Rab and Munc18 isoforms are upregulated in LPS-stimulated macrophages (178). The fusion of vesicular carriers arriving from the TGN to the ERC seems to imply a SNARE complex containing the t-SNAREs Syntaxin 6 and Vtilb as well as the ERC-localized v-SNARE VAMP-3. The PM delivery implies a complex composed of SNAP-23 and Syntaxin 4 as well as VAMP-3 (31). Initial analysis of signaling events during such transport indicate that transport is not simply a default mechanism but to the contrary highly regulated. In particular, LPS allows recruitment of PI3K $\delta$ to the TGN, where it allows recruitment of the GTPase dynamin involved in the fission of budding tubulovesicular structures (179). The phosphocholine cytidylyltransferase involved in lipid biogenesis seems also to get activated during this process (31).

Only a few studies have addressed the vesicular trafficking mechanisms in MC. Generally, they point to the fact that, with the exception of cytokines stored in cytoplasmic granules released by anaphylactic degranulation, they are released in a distinct manner that could resemble the mechanisms worked out in macrophages. Indeed, so far none of the SNARE accessory molecules involved in anaphylactic degranulation has shown an implication in cytokine trafficking. Neither the absence of Munc18-2 (70) nor of Syt II (100) has impacted on the secretion of cytokines such as TNF, IL-6, IL-4, or the chemokine CCL2 into the extracellular medium. The latter implies that calcium-mediated regulation may not play a major role in cytokine trafficking although other Syts expressed in MC (7) have not been tested. Yet, secretion of cytokines/chemokines in MC clearly implies SNARE fusion proteins. In human MC, it was shown that introduction of antibodies directed against PM localized t-SNAREs SNAP-23, Syntaxin 3, and Syntaxin 6 could block secretion in permeabilized human MC of all chemokines tested (CCL2, CCL3, CCL4, and CXCL8) albeit it was not always significant in the case of Syntaxin 6 (71). Anti-Syntaxin 4 and anti-VAMP-8 were able to selectively inhibit CXCL8, which could be explained by the fact that CXCL8 is stored in significant amounts in cytoplasmic granules of human $\mathrm{MC}$ and hence uses SNARE proteins involved in anaphylactic degranulation of human MC (28). No effects were seen neither for anti-Syntaxin 2, which localizes to the cytosol or the lysosomal marker VAMP-7 (71). In murine MC, functional data with SNARE proteins are not yet available, although the implication of VAMP-3 is suggested by the strong colocalization of VAMP-3 containing vesicles with TNF that had been protected against cleavage by a TACE inhibitor, while no colocalization with VAMP-8 containing vesicles was found $(66,180)$. This suggests that TNF may in a similar manner to macrophages take route through the ERC. Alternatively, it may also be delivered via the constitutive secretory pathway. Further studies in MC are however necessary to delineate the various vesicular trafficking events involved.

\section{DISEASES ASSOCIATED WITH SG BIOGENESIS AND VESICULAR TRAFFICKING AND MAST CELL PHENOTYPE}

In addition to the fundamental studies examining the secretory mechanisms of vesicular trafficking some important information has also been obtained from the study of inherited diseases in humans affecting SG biogenesis and secretory mechanisms in immune cells. Due to the associated defects of lymphocyte cytotoxic functions many of these diseases are characterized by a pathological condition called hemophagocytic lymphohistiocytosis (HLH) with defects in cytotoxic activity and expansion of polyclonal CD8-positive T cells and IFN $\gamma$-activated phagocytic macrophages, which infiltrate multiple organs and tissues including the nervous system causing also neurological manifestations [reviewed in Ref. (181)]. Amongst the familial forms of these diseases one can find familial lymphohistiocytosis 1 (FLH1) the most frequent form $(50 \%)$ with still unknown genotype, FLH2 with a defect in the cytotoxic granule protein perforin, FLH3 with a defect in the SNARE accessory protein Munc13-4, FLH4 with a defect in the t-SNARE syntaxin 11, FLH5 with a defect in the SNARE accessory protein STXBP2 (Munc18-2) (181). Additional diseases showing signs of HLH include Griscelli Syndrome 2 (GS2) with a defect in Rab27A, Chediak-Higashi syndrome characterized by the presence of giant secretory lysosomes and a defect in the Lysosomal trafficking regulator (Lyst) gene (181). Another disease complex with secretory phenotypes is the Hermansky-Pudlak syndrome a heterogenous conditions leading to with different types of mutations in genes (HPS1, AP3B1, HPS3, HPS4, HPS5, HPS6, DTNBP1, $B L O C 1 S 3$, and BlOC1S6) (182). Except for AP3B1 their protein products are part of the Biogenesis of Lysosome-related Organelles Complexes (BLOC), which regulates the traffic of vesicles in the endosomal system and also participate in endosomal membrane secretory lysosome fusion. Clinically the diseases are characterized by platelet secretory dysfunctions with altered granules and oculocutaneous albinism, pulmonary fibrosis, and granulomatous colitis (182). However, only defects in AP3B1, which is part of the AP-3 adaptor complex involved in the formation of new vesicles at the Golgi complex is also associated with lymphohistiocytosis and immune deficiency.

While the MCs phenotype has not been studied in human diseases some knowledge has been obtained from MCs obtained from mice carrying equivalent mutations. We have already described the effect of Munc13-4, Syntaxin 11, Munc18-2, and Rab27 mutations, which except for Syntaxin 11 all show a secretory phenotype. However, this generally concerns only anaphylactic degranulation, while for example cytokine/chemokine production seems not to be affected for example in Munc18-2 deficient cells (see above). Some earlier studies have also analyzed the effect of LYST mutations in MCs obtained from the beige mouse model. LYST codes for a ubiquitously expressed huge $(425 \mathrm{kDa})$ cytosolic protein belonging to the $\mathrm{BEACH}$ (beige and Chediak-Higashi) family of proteins, which are proteins involved in vesicular trafficking and synaptic transmission, although their exact function is still unknown. Interestingly, LYST interaction partners include proteins involved, which are part of the ESCRT complex, suggesting a role of Lyst in the formation of intraluminal vesicles. Alternatively, data from the beige mouse model with a defect in LYST or LYST overexpression data indicate that LYST could be important in vesicle generation by fission (183). Indeed, MCs obtained from beige mouse are characterized largely increased giant granules (about $18 \times$ the volume), while granules of pancreatic acinar cells showed only a minor increase (23\%) (184), suggesting that this may apply specifically to secretory lysosomes as granules from other hematopoietic cells are 
also increased (183). Furthermore, granule composition appeared to be normal (185). Functional studies also showed that beige MCs were degranulation competent but seemed to show a higher frequency of granule-granule fusion events (186). Electrophysiological studies showed that membrane capacitance increases were about 10-fold higher in beige MCs in agreement with the large granule size (118).

Concerning Hermansky-Pudlak syndrome (HPS) only one elecrophysiological study has been performed with MCs from the ruby-eye mouse showing a defect in HPS6. HSP6 is part of the BLOC-2 complex composed of HSP3, HSP5, and HSP6. Patients with defects in BLOC-2 show a somewhat milder phenotype with absence of the development of pulmonary fibrosis. It interacts with BLOC-1 (DTNBP1, BLOC1S3, and BlOC1S6) required for cargo-specific sorting from early endosomes to lysosomerelated organelles (187). In MCs derived from the ruby-eye mouse model a fusion pore phenotype was observed in electrophysiological studies with a threefold increase in the fraction and duration of transient fusion events (188). This suggests that HPS6 and potentially BLOC-2 may also play a direct role in secretion. The increased number of transient fusion events may also be an explanation for the observed platelet granule storage deficiency.

\section{CONCLUDING REMARIKS}

The secretion of inflammatory mediators by MC through vesicular carriers is a highly regulated process starting with the biogenesis of SGs. Release is triggered by the activation of cell surface receptors initiating signaling processes culminating in the release from cytoplasmic granules by anaphylactic degranulation. As shown in this review many new signaling effectors have been described regulating the various steps involved in SG biogenesis and secretion. De novo production of cytokine requires additional control mechanisms at the level of transcriptional and post-transcriptional control of protein synthesis but as new data show may also be regulated at the level of vesicular trafficking, differing from the ones involved in the control of anaphylactic degranulation.

In addition, evidence has shown that MCs are receptive to a number of outside agents activating signaling pathways able to modulate the capacity of MC for secretion. These include, for example immunosuppressive cytokines like the members of the IL10 family and the TGF- $\beta$ superfamily (TGF $\beta$ and activins) (189). Certain Fc receptors have been also shown to negatively control signaling responses induced by MC $(190,191)$. Certain GPCRs coupled to Gs proteins that induce the production of cyclic AMP (such as $\beta 2$-adrenergic, A2, and $\mathrm{PGE}_{2}$ receptors), (192) or opiates acting through $\delta$ - or $\mu$ opiate receptors can also be potent inhibitors of MC secretion (193).

Together, this shows the necessity for exquisite control of the MC secretory processes in order to avoid the dangerous consequences it may have.

\section{ACKNOWLEDGMENTS}

This work was supported by an International collaboration grant between ANR France (ANR-12-ISV3-0006-01 and Conacyt Mexico (Conacyt-ANR 188565). This research project has also been supported by the Investissements d'Avenir programme ANR-11-IDEX-0005-02, Sorbonne Paris Cite, Laboratoire d'excellence INFLAMEX.

\section{REFERENCES}

1. Galli SJ, Grimbaldeston M, Tsai M. Immunomodulatory mast cells: negative, as well as positive, regulators of immunity. Nat Rev Immunol (2008) 8:478-86. doi: $10.1038 /$ nri2327

2. Abraham SN, St John AL. Mast cell-orchestrated immunity to pathogens. Nat Rev Immunol (2010) 10:440-52. doi:10.1038/nri2782

3. Blank U, Rivera J. The ins and outs of IgE-dependent mast-cell exocytosis. Trends Immunol (2004) 25:266-73. doi:10.1016/j.it.2004.03.005

4. Galli SJ, Nakae S, Tsai M. Mast cells in the development of adaptive immune responses. Nat Immunol (2005) 6:135-42. doi:10.1038/ni1158

5. Wernersson S, Pejler G. Mast cell secretory granules: armed for battle. Nat Rev Immunol (2014) 14:478-94. doi:10.1038/nri3690

6. Gilfillan AM, Beaven MA. Regulation of mast cell responses in health and disease. Crit Rev Immunol (2011) 31:475-529. doi:10.1615/CritRevImmunol.v31. i6.30

7. Sagi-Eisenberg R. The mast cell: where endocytosis and regulated exocytosis meet. Immunol Rev (2007) 217:292-303. doi:10.1111/j.1600-065X 2007.00516.x

8. Benhamou M, Blank U. Stimulus-secretion coupling by high-affinity IgE receptor: new developments. FEBS Lett (2010) 584:4941-8. doi:10.1016/j.febslet. 2010.09.023

9. Marshall JS. Mast-cell responses to pathogens. Nat Rev Immunol (2004) 4:787-99. doi:10.1038/nri1460

10. Gonzalez-Espinosa C, Odom S, Olivera A, Hobson JP, Martinez ME, OliveiraDos-Santos A, et al. Preferential signaling and induction of allergy-promoting lymphokines upon weak stimulation of the high affinity IgE receptor on mast cells. J Exp Med (2003) 197:1453-65. doi:10.1084/jem.20021806

11. Suzuki R, Leach S, Liu W, Ralston E, Scheffel J, Zhang W, et al. Molecular editing of cellular responses by the high-affinity receptor for IgE. Science (2014) 343:1021-5. doi:10.1126/science. 1246976

12. Blobel G. How proteins move across the endoplasmic reticulum membrane. Hepatology (1987) 7:26S-9S. doi:10.1002/hep.1840070705

13. Glick BS, Luini A. Models for Golgi traffic: a critical assessment. Cold Spring Harb Perspect Biol (2011) 3:a005215. doi:10.1101/cshperspect.a005215

14. Arvan P, Castle D. Sorting and storage during secretory granule biogenesis: looking backward and looking forward. Biochem J (1998) 332(Pt 3):593-610.

15. Tooze SA, Martens GJ, Huttner WB. Secretory granule biogenesis: rafting to the SNARE. Trends Cell Biol (2001) 11:116-22. doi:10.1016/S0962-8924(00) 01907-3

16. De Matteis MA, Luini A. Exiting the Golgi complex. Nat Rev Mol Cell Biol (2008) 9:273-84. doi:10.1038/nrm2378

17. Braulke T, Bonifacino JS. Sorting of lysosomal proteins. Biochim Biophys Acta (2009) 1793:605-14. doi:10.1016/j.bbamcr.2008.10.016

18. Schmidt O, Teis D. The ESCRT machinery. Curr Biol (2012) 22:R116-20. doi:10.1016/j.cub.2012.01.028

19. Blott EJ, Griffiths GM. Secretory lysosomes. Nat Rev Mol Cell Biol (2002) 3:122-31. doi:10.1038/nrm732

20. Marks MS, Heijnen HF, Raposo G. Lysosome-related organelles: unusual compartments become mainstream. Curr Opin Cell Biol (2013) 25:495-505. doi:10.1016/j.ceb.2013.04.008

21. De Saint Basile G, Menasche G, Fischer A. Molecular mechanisms of biogenesis and exocytosis of cytotoxic granules. Nat Rev Immunol (2010) 10:568-79. doi:10.1038/nri2803

22. Blair EA, Castle AM, Castle JD. Proteoglycan sulfation and storage parallels storage of basic secretory proteins in exocrine cells. Am J Physiol (1991) 261:C897-905.

23. Henningsson F, Hergeth S, Cortelius R, Abrink M, Pejler G. A role for serglycin proteoglycan in granular retention and processing of mast cell secretory granule components. FEBS J (2006) 273:4901-12. doi:10.1111/j.1742-4658.2006. 05489.x

24. Raposo G, Tenza D, Mecheri S, Peronet R, Bonnerot C, Desaymard C. Accumulation of major histocompatibility complex class II molecules in mast cell secretory granules and their release upon degranulation. Mol Biol Cell (1997) 8:2631-45. doi:10.1091/mbc.8.12.2631 
25. Grimberg E, Peng Z, Hammel I, Sagi-Eisenberg R. Synaptotagmin III is a critical factor for the formation of the perinuclear endocytic recycling compartment and determination of secretory granules size. J Cell Sci (2003) 116:145-54. doi:10.1242/jcs.00186

26. Azouz NP, Zur N, Efergan A, Ohbayashi N, Fukuda M, Amihai D, et al. Rab5 is a novel regulator of mast cell secretory granules: impact on size, cargo, and exocytosis. J Immunol (2014) 192:4043-53. doi:10.4049/jimmunol.1302196

27. Haberman Y, Ziv I, Gorzalczany Y, Hirschberg K, Mittleman L, Fukuda M, et al. Synaptotagmin (Syt) IX is an essential determinant for protein sorting to secretory granules in mast cells. Blood (2007) 109:3385-92. doi:10.1182/ blood-2006-07-033126

28. Sander LE, Frank SP, Bolat S, Blank U, Galli T, Bigalke H, et al. Vesicle associated membrane protein (VAMP)-7 and VAMP-8, but not VAMP-2 or VAMP-3, are required for activation-induced degranulation of mature human mast cells. Eur J Immunol (2008) 38:855-63. doi:10.1002/eji.200737634

29. Hammel I, Lagunoff D, Galli SJ. Regulation of secretory granule size by the precise generation and fusion of unit granules. J Cell Mol Med (2010) 14:1904-16. doi:10.1111/j.1582-4934.2010.01071.x

30. Hallgren J, Gurish MF. Granule maturation in mast cells: histamine in control. Eur J Immunol (2014) 44:33-6. doi:10.1002/eji.201344262

31. Stow JL, Murray RZ. Intracellular trafficking and secretion of inflammatory cytokines. Cytokine Growth Factor Rev (2013) 24:227-39. doi:10.1016/j.cytogfr. 2013.04.001

32. Dvorak AM, Massey W, Warner J, Kissell S, Kagey-Sobotka A, Lichtenstein LM. IgE-mediated anaphylactic degranulation of isolated human skin mast cells. Blood (1991) 77:569-78.

33. Röhlich P, Anderson P, Uvnäs B. Electron microscope observation on compound 48/80-induced degranulation in mast cells. J Cell Biol (1971) 51:465-83. doi:10.1083/jcb.51.2.465

34. Stevens RL, Adachi R. Protease-proteoglycan complexes of mouse and human mast cells and importance of their beta-tryptase-heparin complexes in inflammation and innate immunity. Immunol Rev (2007) 217:155-67. doi:10.1111/j. 1600-065X.2007.00525.x

35. Ehrlich P. Beiträge zur Theorie und Praxis histologischer Färbung. Deutschland: Doktorarbeit, Universität Leipzig (1878).

36. Pejler G, Abrink M, Ringvall M, Wernersson S. Mast cell proteases. Adv Immunol (2007) 95:167-255. doi:10.1016/S0065-2776(07)95006-3

37. Hammel I, Meilijson I. The stealthy nano-machine behind mast cell granule size distribution. Mol Immunol (2014). doi:10.1016/j.molimm.2014.02.005

38. Marchand F, Mecheri S, Guilloux L, Iannascoli B, Weyer A, Blank U. Human serum IgE-mediated mast cell degranulation shows poor correlation to allergen-specific IgE content. Allergy (2003) 58:1037-43. doi:10.1034/j.13989995.2003.00251.x

39. Galli SJ, Tsai M, Piliponsky AM. The development of allergic inflammation. Nature (2008) 454:445-54. doi:10.1038/nature07204

40. Alvarez De Toledo G, Fernandez J. Compound versus multigranular exocytosis in peritoneal cells. J Gen Physiol (1990) 95:397-402. doi:10.1085/ jgp.95.3.397

41. Dvorak AM. Ultrastructural features of human basophil and mast cell secretory function. In: Marone GL, Galli LM, editors. Mast Cells and Basophils. London: Academic Press (2000). p. 63-88.

42. Gordon JR, Galli SJ. Mast cells as a source of both preformed and immunologically inducible TNF-alpha/cachectin. Nature (1990) 346:274-6. doi:10.1038/ 346274a0

43. Pelletier C, Varin-Blank N, Rivera J, Iannascoli B, Marchand F, David B, et al. Fc epsilonRI-mediated induction of TNF-alpha gene expression in the RBL- $2 \mathrm{H} 3$ mast cell line: regulation by a novel NF-kappaB-like nuclear binding complex. J Immunol (1998) 161:4768-76.

44. Olszewski MB, Trzaska D, Knol EF, Adamczewska V, Dastych J. Efficient sorting of TNF-alpha to rodent mast cell granules is dependent on N-linked glycosylation. Eur J Immunol (2006) 36:997-1008. doi:10.1002/eji.200535323

45. Olszewski MB, Groot AJ, Dastych J, Knol EF. TNF trafficking to human mast cell granules: mature chain-dependent endocytosis. JImmunol (2007) 178:5701-9. doi:10.4049/jimmunol.178.9.5701

46. Bjerke T, Gaustadnes M, Nielsen S, Nielsen LP, Schiotz PO, Rudiger N, et al. Human blood eosinophils produce and secrete interleukin 4. Respir Med (1996) 90:271-7. doi:10.1016/S0954-6111(96)90098-0
47. Lacy P, Mahmudi-Azer S, Bablitz B, Hagen SC, Velazquez JR, Man SF, et al. Rapid mobilization of intracellularly stored RANTES in response to interferongamma in human eosinophils. Blood (1999) 94:23-32.

48. Bliss SK, Butcher BA, Denkers EY. Rapid recruitment of neutrophils containing prestored IL-12 during microbial infection. J Immunol (2000) 165:4515-21. doi:10.4049/jimmunol.165.8.4515

49. Flad HD, Brandt E. Platelet-derived chemokines: pathophysiology and therapeutic aspects. Cell Mol Life Sci (2010) 67:2363-86. doi:10.1007/s00018-0100306-x

50. Jonsson F, Mancardi DA, Kita Y, Karasuyama H, Iannascoli B, Van Rooijen N, et al. Mouse and human neutrophils induce anaphylaxis. J Clin Invest (2011) 121:1484-96. doi:10.1172/JCI45232

51. Gilfillan AM, Tkaczyk C. Integrated signalling pathways for mast-cell activation. Nat Rev Immunol (2006) 6:218-30. doi:10.1038/nri1782

52. Kim MS, Radinger M, Gilfillan AM. The multiple roles of phosphoinositide 3-kinase in mast cell biology. Trends Immunol (2008) 29:493-501. doi:10.1016/j.it.2008.07.004

53. Gilfillan AM, Rivera J. The tyrosine kinase network regulating mast cell activation. Immunol Rev (2009) 228:149-69. doi:10.1111/j.1600-065X.2008.00742.x

54. Blank U, Cyprien B, Martin-Verdeaux S, Paumet F, Pombo I, Rivera J, et al. SNAREs and associated regulators in the control of exocytosis in the RBL-2H3 mast cell line. Mol Immunol (2002) 38:1341-5. doi:10.1016/S0161-5890(02) 00085-8

55. Hong W. SNAREs and traffic. Biochim Biophys Acta (2005) 1744:120-44. doi:10.1016/j.bbamcr.2005.03.014

56. Sudhof TC, Rothman JE. Membrane fusion: grappling with SNARE and SM proteins. Science (2009) 323:474-7. doi:10.1126/science.1161748

57. Lorentz A, Baumann A, Vitte J, Blank U. The SNARE machinery in mast cell secretion. Front Immunol (2012) 3:143. doi:10.3389/fimmu.2012.00143

58. Weber T, Zemelman BV, Mcnew JA, Westermann B, Gmachl M, Parlati F, et al. Snarepins - minimal machinery for membrane fusion. Cell (1998) 92:759-72. doi:10.1016/S0092-8674(00)81404-X

59. Sudhof TC. Neurotransmitter release: the last millisecond in the life of a synaptic vesicle. Neuron (2013) 80:675-90. doi:10.1016/j.neuron.2013.10.022

60. Guo Z, Turner C, Castle D. Relocation of the t-SNARE SNAP-23 from lamellipodia-like cell surface projections regulates compound exocytosis in mast cells. Cell (1998) 94:537-48. doi:10.1016/S0092-8674(00)81594-9

61. Paumet F, Le Mao J, Martin S, Galli T, David B, Blank U, et al. Soluble NSF attachment protein receptors (SNAREs) in RBL-2H3 mast cells: functional role of syntaxin 4 in exocytosis and identification of a vesicle-associated membrane protein 8-containing secretory compartment. J Immunol (2000) 164:5850-7. doi:10.4049/jimmunol.164.11.5850

62. Vaidyanathan VV, Puri N, Roche PA. The last exon of SNAP-23 regulates granule exocytosis from mast cells. J Biol Chem (2001) 276:25101-6. doi:10.1074/jbc.M103536200

63. Puri N, Kruhlak MJ, Whiteheart SW, Roche PA. Mast cell degranulation requires $\mathrm{N}$-ethylmaleimide-sensitive factor-mediated SNARE disassembly. J Immunol (2003) 171:5345-52. doi:10.4049/jimmunol.171.10.5345

64. Puri N, Roche PA. Ternary SNARE complexes are enriched in lipid rafts during mast cell exocytosis. Traffic (2006) 7:1482-94. doi:10.1111/j.1600-0854.2006. 00490.x

65. Puri N, Roche PA. Mast cells possess distinct secretory granule subsets whose exocytosis is regulated by different SNARE isoforms. Proc Natl Acad Sci U S A (2008) 105:2580-5. doi:10.1073/pnas.0707854105

66. Tiwari N, Wang CC, Brochetta C, Ke G, Vita F, Qi Z, et al. VAMP-8 segregates mast cell-preformed mediator exocytosis from cytokine trafficking pathways. Blood (2008) 111:3665-74. doi:10.1182/blood-2007-07-103309

67. Wong SH, Zhang T, Xu Y, Subramaniam VN, Griffiths G, Hong W. Endobrevin, a novel synaptobrevin/VAMP-like protein preferentially associated with the early endosome. Mol Biol Cell (1998) 9:1549-63. doi:10.1091/mbc. 9.6.1549

68. Miesenbock G, De Angelis DA, Rothman JE. Visualizing secretion and synaptic transmission with $\mathrm{pH}$-sensitive green fluorescent proteins. Nature (1998) 394:192-5. doi:10.1038/28190

69. Hibi T, Hirashima N, Nakanishi M. Rat basophilic leukemia cells express syntaxin-3 and VAMP-7 in granule membranes. Biochem Biophys Res Commun (2000) 271:36-41. doi:10.1006/bbrc.2000.2591 
70. Brochetta C, Suzuki R, Vita F, Soranzo MR, Claver J, Madjene LC, et al. Munc182 and syntaxin 3 control distinct essential steps in mast cell degranulation. J Immunol (2014) 192:41-51. doi:10.4049/jimmunol.1301277

71. Frank SP, Thon KP, Bischoff SC, Lorentz A. SNAP-23 and syntaxin-3 are required for chemokine release by mature human mast cells. Mol Immunol (2011) 49:353-8. doi:10.1016/j.molimm.2011.09.011

72. Stenmark H. Rab GTPases as coordinators of vesicle traffic. Nat Rev Mol Cell Biol (2009) 10:513-25. doi:10.1038/nrm2728

73. Azouz NP, Matsui T, Fukuda M, Sagi-Eisenberg R. Decoding the regulation of mast cell exocytosis by networks of Rab GTPases. J Immunol (2012) 189:2169-80. doi:10.4049/jimmunol.1200542

74. Mizuno K, Tolmachova T, Ushakov DS, Romao M, Abrink M, Ferenczi MA, et al. Rab27b regulates mast cell granule dynamics and secretion. Traffic (2007) 8:883-92. doi:10.1111/j.1600-0854.2007.00571.x

75. Singh RK, Mizuno K, Wasmeier C, Wavre-Shapton ST, Recchi C, Catz SD, et al. Distinct and opposing roles for Rab27a/Mlph/MyoVa and Rab27b/Munc13-4 in mast cell secretion. FEBS J (2013) 280:892-903. doi:10.1111/febs.12081

76. Neeft M, Wieffer M, De Jong AS, Negroiu G, Metz CH, Van Loon A, et al. Munc13-4 is an effector of rab27a and controls secretion of lysosomes in hematopoietic cells. Mol Biol Cell (2005) 16:731-41. doi:10.1091/mbc.E0410-0923

77. Elstak ED, Neeft M, Nehme NT, Voortman J, Cheung M, Goodarzifard $\mathrm{M}$, et al. The munc13-4-rab27 complex is specifically required for tethering secretory lysosomes at the plasma membrane. Blood (2011) 118:1570-8. doi:10.1182/blood-2011-02-339523

78. Smith J, Thompson N, Armstrong J, Hayes B, Crofts A, Squire J, et al. Rat basophilic leukaemia (RBL) cells overexpressing rab3a have a reversible block in antigen-stimulated exocytosis. Biochem J (1997) 323:321-8.

79. Roa M, Paumet F, Lemao J, David B, Blank U. Involvement of the ras-like GTPase rab3d in RBL-2H3 mast cell exocytosis following stimulation via high affinity IgE receptors (Fc epsilon RI). J Immunol (1997) 159:2815-23.

80. Coppola T, Perret-Menoud V, Gattesco S, Magnin S, Pombo I, Blank U, et al. The death domain of Rab3 guanine nucleotide exchange protein in GDP/GTP exchange activity in living cells. Biochem J (2002) 362:273-9. doi:10.1042/0264-6021:3620273

81. Tuvim MJ, Adachi R, Chocano JF, Moore RH, Lampert RM, Zera E, et al. Rab3D, a small GTPase, is localized on mast cell secretory granules and translocates to the plasma membrane upon exocytosis. Am J Respir Cell Mol Biol (1999) 20:79-89. doi:10.1165/ajrcmb.20.1.3279

82. Riedel D, Antonin W, Fernandez-Chacon R, Alvarez De Toledo G, Jo T, Geppert $\mathrm{M}$, et al. Rab3D is not required for exocrine exocytosis but for maintenance of normally sized secretory granules. Mol Cell Biol (2002) 22:6487-97. doi:10.1128/MCB.22.18.6487-6497.2002

83. Burgoyne RD, Barclay JW, Ciufo LF, Graham ME, Handley MT, Morgan A. The functions of Munc18-1 in regulated exocytosis. Ann N Y Acad Sci (2009) 1152:76-86. doi:10.1111/j.1749-6632.2008.03987.x

84. Xu Y, Su L, Rizo J. Binding of Munc18-1 to synaptobrevin and to the SNARE four-helix bundle. Biochemistry (2010) 49:1568-76. doi:10.1021/bi9021878

85. Martin-Verdeaux S, Pombo I, Iannascoli B, Roa M, Varin-Blank N, Rivera J, et al. Analysis of Munc18-2 compartmentation in mast cells reveals a role for microtubules in granule exocytosis. J Cell Sci (2003) 116:325-34. doi:10.1242/jcs.00216

86. Pombo I, Rivera J, Blank U. Munc18-2/syntaxin3 complexes are spatially separated from syntaxin3-containing SNARE complexes. FEBS Lett (2003) 550:144-8. doi:10.1016/S0014-5793(03)00864-0

87. Wu Z, Macneil AJ, Berman JN, Lin TJ. Syntaxin binding protein 1 is not required for allergic inflammation via IgE-mediated mast cell activation. PLoS One (2013) 8:e58560. doi:10.1371/journal.pone.0058560

88. Tadokoro S, Kurimoto T, Nakanishi M, Hirashima N. Munc18-2 regulates exocytotic membrane fusion positively interacting with syntaxin-3 in RBL-2H3 cells. Mol Immunol (2007) 44:3427-33. doi:10.1016/j.molimm.2007.02.013

89. Bin NR, Jung CH, Piggott C, Sugita S. Crucial role of the hydrophobic pocket region of Munc18 protein in mast cell degranulation. Proc Natl Acad Sci U S A (2013) 110:4610-5. doi:10.1073/pnas.1214887110

90. Cote M, Menager MM, Burgess A, Mahlaoui N, Picard C, Schaffner C, et al. Munc18-2 deficiency causes familial hemophagocytic lymphohistiocytosis type 5 and impairs cytotoxic granule exocytosis in patient NK cells. J Clin Invest (2009) 119:3765-73. doi:10.1172/JCI40732
91. Brochetta C, Vita F, Tiwari N, Scandiuzzi L, Soranzo MR, Guerin-Marchand $\mathrm{C}$, et al. Involvement of Munc18 isoforms in the regulation of granule exocytosis in neutrophils. Biochim Biophys Acta (2008) 1783:1781-91. doi:10.1016/ j.bbamcr.2008.05.023

92. Voets T, Toonen RF, Brian EC, De Wit H, Moser T, Rettig J, et al. Munc181 promotes large dense-core vesicle docking. Neuron (2001) 31:581-91. doi:10.1016/S0896-6273(01)00391-9

93. Chua JJ, Butkevich E, Worseck JM, Kittelmann M, Gronborg M, Behrmann E, et al. Phosphorylation-regulated axonal dependent transport of syntaxin 1 is mediated by a Kinesin-1 adapter. Proc Natl Acad Sci U S A (2012) 109:5862-7. doi:10.1073/pnas.1113819109

94. Castle JD, Guo Z, Liu L. Function of the t-SNARE SNAP-23 and secretory carrier membrane proteins (SCAMPs) in exocytosis in mast cells. Mol Immunol (2002) 38:1337-40. doi:10.1016/S0161-5890(02)00084-6

95. Guo Z, Liu L, Cafiso D, Castle D. Perturbation of a very late step of regulated exocytosis by a secretory carrier membrane protein (SCAMP2)-derived peptide. J Biol Chem (2002) 277:35357-63. doi:10.1074/jbc.M202259200

96. Liu L, Guo Z, Tieu Q, Castle A, Castle D. Role of secretory carrier membrane protein SCAMP2 in granule exocytosis. Mol Biol Cell (2002) 13:4266-78. doi:10.1091/mbc.E02-03-0136

97. Peng Z, Beaven MA. An essential role for phospholipase D in the activation of protein kinase C and degranulation in mast cells. JImmunol (2005) 174:5201-8. doi:10.4049/jimmunol.174.9.5201

98. Rizo J, Rosenmund C. Synaptic vesicle fusion. Nat Struct Mol Biol (2008) 15:665-74. doi:10.1038/nsmb.1450

99. Baram D, Adachi R, Medalia O, Tuvim M, Dickey BF, Mekori YA, et al. Synaptotagmin II negatively regulates Ca2+-triggered exocytosis of lysosomes in mast cells. J Exp Med (1999) 189:1649-58. doi:10.1084/jem.189.10.1649

100. Melicoff E, Sansores-Garcia L, Gomez A, Moreira DC, Datta P, Thakur P, et al. Synaptotagmin-2 controls regulated exocytosis but not other secretory responses of mast cells. J Biol Chem (2009) 284:19445-51. doi:10.1074/jbc. M109.002550

101. Tadokoro S, Nakanishi M, Hirashima N. Complexin II facilitates exocytotic release in mast cells by enhancing $\mathrm{Ca} 2+$ sensitivity of the fusion process. $J$ Cell Sci (2005) 118:2239-46. doi:10.1242/jcs.02338

102. Tadokoro S, Nakanishi M, Hirashima N. Complexin II regulates degranulation in RBL-2H3 cells by interacting with SNARE complex containing syntaxin-3. Cell Immunol (2010) 261:51-6. doi:10.1016/j.cellimm.2009.10.011

103. Sato M, Mori Y, Matsui T, Aoki R, Oya M, Yanagihara Y, et al. Role of the polybasic sequence in the Doc2alpha C2B domain in dense-core vesicle exocytosis in PC12 cells. J Neurochem (2010) 114:171-81. doi:10.1111/j.1471-4159.2010. 06739.x

104. Higashio H, Nishimura N, Ishizaki H, Miyoshi J, Orita S, Sakane A, et al. Doc2 alpha and Munc13-4 regulate $\mathrm{Ca}(2+)$-dependent secretory lysosome exocytosis in mast cells. J Immunol (2008) 180:4774-84. doi:10.4049/jimmunol.180.7. 4774

105. Pombo I, Martin-Verdeaux S, Iannascoli B, Le Mao J, Deriano L, Rivera J, et al. IgE receptor type I-dependent regulation of a Rab3D-associated kinase: a possible link in the calcium-dependent assembly of SNARE complexes. JBiol Chem (2001) 276:42893-900. doi:10.1074/jbc.M103527200

106. Suzuki K, Verma IM. Phosphorylation of SNAP-23 by IkappaB kinase 2 regulates mast cell degranulation. Cell (2008) 134:485-95. doi:10.1016/j.cell.2008. 05.050

107. Dvorak HF, Dvorak AM. Basophilic leukocytes in delayed-type hypersensitivity reactions in experimental animals and man. Adv Exp Med Biol (1973) 29:573-9. doi:10.1007/978-1-4615-9017-0_83

108. Crivellato E, Nico B, Mallardi F, Beltrami CA, Ribatti D. Piecemeal degranulation as a general secretory mechanism? Anat Rec A Discov Mol Cell Evol Biol (2003) 274:778-84. doi:10.1002/ar.a.10095

109. Dvorak HF, Dvorak AM. Basophilic leucocytes: structure, function and role in disease. Clin Haematol (1975) 4:651-83.

110. Dvorak AM, Mcleod RS, Onderdonk A, Monahan-Earley RA, Cullen JB, Antonioli DA, et al. Ultrastructural evidence for piecemeal and anaphylactic degranulation of human gut mucosal mast cells in vivo. Int Arch Allergy Immunol (1992) 99:74-83. doi:10.1159/000236338

111. Dvorak A, Tepper R, Weller P, Morgan E, Estrella P, Monahan-Earley R, et al. Piecemeal degranulation of mast cells in the inflammatory eyelid lesions of interleukin-4 transgenic mice. Evidence of mast cell histamine release in vivo 
by diamine oxidase-gold enzyme affinity ultrastructural cytochemistry. Blood (1994) 83:3600-12.

112. Kandere-Grzybowska K, Letourneau R, Kempuraj D, Donelan J, Poplawski S, Boucher W, et al. IL-1 induces vesicular secretion of IL-6 without degranulation from human mast cells. J Immunol (2003) 171:4830-6. doi:10.4049/jimmunol. 171.9.4830

113. Alabi AA, Tsien RW. Perspectives on kiss-and-run: role in exocytosis, endocytosis, and neurotransmission. Annu Rev Physiol (2013) 75:393-422. doi:10. 1146/annurev-physiol-020911-153305

114. Taraska JW, Perrais D, Ohara-Imaizumi M, Nagamatsu S, Almers W. Secretory granules are recaptured largely intact after stimulated exocytosis in cultured endocrine cells. Proc Natl Acad Sci U S A (2003) 100:2070-5. doi:10.1073/pnas.0337526100

115. Perrais D, Kleppe IC, Taraska JW, Almers W. Recapture after exocytosis causes differential retention of protein in granules of bovine chromaffin cells. JPhysiol (2004) 560:413-28. doi:10.1113/jphysiol.2004.064410

116. Tsuboi T, Mcmahon HT, Rutter GA. Mechanisms of dense core vesicle recapture following "kiss and run" ("cavicapture") exocytosis in insulin-secreting cells. J Biol Chem (2004) 279:47115-24. doi:10.1074/jbc.M408179200

117. Fernandez J, Neher E, Gomperts B. Capacitance measurements reveal stepwise fusion events in degranulating mast cells. Nature (1984) 312:453-5. doi:10.1038/312453a0

118. Breckenridge LJ, Almers W. Final steps in exocytosis observed in a cell with giant secretory granules. Proc Natl Acad Sci U S A (1987) 84:1945-9. doi:10.1073/pnas.84.7.1945

119. Williams RM, Webb WW. Single granule $\mathrm{pH}$ cycling in antigen-induced mast cell secretion. J Cell Sci (2000) 113:3839-50.

120. Elhamdani A, Azizi F, Artalejo CR. Double patch clamp reveals that transient fusion (kiss-and-run) is a major mechanism of secretion in calf adrenal chromaffin cells: high calcium shifts the mechanism from kiss-and-run to complete fusion. J Neurosci (2006) 26:3030-6. doi:10.1523/JNEUROSCI.5275-05.2006

121. Shi L, Shen QT, Kiel A, Wang J, Wang HW, Melia TJ, et al. SNARE proteins: one to fuse and three to keep the nascent fusion pore open. Science (2012) 335:1355-9. doi:10.1126/science.1214984

122. Wang CT, Lu JC, Bai J, Chang PY, Martin TF, Chapman ER, et al. Different domains of synaptotagmin control the choice between kiss-and-run and full fusion. Nature (2003) 424:943-7. doi:10.1038/nature01857

123. Archer DA, Graham ME, Burgoyne RD. Complexin regulates the closure of the fusion pore during regulated vesicle exocytosis. J Biol Chem (2002) 277:18249-52. doi:10.1074/jbc.C200166200

124. Gerachshenko T, Blackmer T, Yoon EJ, Bartleson C, Hamm HE, Alford S. Gbetagamma acts at the $\mathrm{C}$ terminus of SNAP-25 to mediate presynaptic inhibition. Nat Neurosci (2005) 8:597-605. doi:10.1038/nn1439

125. Wu LG, Hamid E, Shin W, Chiang HC. Exocytosis and endocytosis: modes, functions, and coupling mechanisms. Annu Rev Physiol (2014) 76:301-31. doi:10.1146/annurev-physiol-021113-170305

126. Cabeza JM, Acosta J, Ales E. Mechanisms of granule membrane recapture following exocytosis in intact mast cells. J Biol Chem (2013) 288:20293-305. doi:10.1074/jbc.M113.459065

127. Hanson PI, Roth R, Morisaki H, Jahn R, Heuser JE. Structure and conformational changes in NSF and its membrane receptor complexes visualized by quick-freeze/deep-etch electron microscopy. Cell (1997) 90:523-35. doi:10.1016/S0092-8674(00)80512-7

128. Boyce JA. Mast cells and eicosanoid mediators: a system of reciprocal paracrine and autocrine regulation. Immunol Rev (2007) 217:168-85. doi:10.1111/j. 1600-065X.2007.00512.x

129. Muller MR, Rao A. NFAT, immunity and cancer: a transcription factor comes of age. Nat Rev Immunol (2010) 10:645-56. doi:10.1038/nri2818

130. Klein M, Klein-Hessling S, Palmetshofer A, Serfling E, Tertilt C, Bopp T, et al. Specific and redundant roles for NFAT transcription factors in the expression of mast cell-derived cytokines. J Immunol (2006) 177:6667-74. doi:10.4049/jimmunol.177.10.6667

131. Gwack Y, Feske S, Srikanth S, Hogan PG, Rao A. Signalling to transcription: store-operated Ca2+ entry and NFAT activation in lymphocytes. Cell Calcium (2007) 42:145-56. doi:10.1016/j.ceca.2007.03.007

132. Napetschnig J, Wu H. Molecular basis of NF-kappaB signaling. Annu Rev Biophys (2013) 42:443-68. doi:10.1146/annurev-biophys-083012-130338
133. Hoesel B, Schmid JA. The complexity of NF-kappaB signaling in inflammation and cancer. Mol Cancer (2013) 12:86. doi:10.1186/1476-4598$12-86$

134. Su TT, Guo B, Kawakami Y, Sommer K, Chae K, Humphries LA, et al. PKC-beta controls I kappa B kinase lipid raft recruitment and activation in response to BCR signaling. Nat Immunol (2002) 3:780-6. doi:10.1038/ni823

135. Klemm S, Gutermuth J, Hultner L, Sparwasser T, Behrendt H, Peschel C, et al. The Bcl10-Malt1 complex segregates Fc epsilon RI-mediated nuclear factor kappa B activation and cytokine production from mast cell degranulation. J Exp Med (2006) 203:337-47. doi:10.1084/jem.20051982

136. Kalesnikoff J, Baur N, Leitges M, Hughes MR, Damen JE, Huber M, et al. SHIP negatively regulates IgE + antigen-induced IL-6 production in mast cells by inhibiting NF-kappa B activity. J Immunol (2002) 168:4737-46. doi:10.4049/jimmunol.168.9.4737

137. Pelletier C, Guerin-Marchand C, Iannascoli B, Marchand F, David B, Weyer A, et al. Specific signaling pathways in the regulation of TNF-alpha mRNA synthesis and TNF-alpha secretion in RBL-2H3 mast cells stimulated through the high affinity IgE receptor. Inflamm Res (1998) 47:493-500. doi:10.1007/ s000110050364

138. Siraganian RP, De Castro RO, Barbu EA, Zhang J. Mast cell signaling: the role of protein tyrosine kinase Syk, its activation and screening methods for new pathway participants. FEBS Lett (2010) 584:4933-40. doi:10.1016/j.febslet.2010.08. 006

139. Schonthaler HB, Guinea-Viniegra J, Wagner EF. Targeting inflammation by modulating the Jun/AP-1 pathway. Ann Rheum Dis (2011) 70(Suppl 1):i109-12. doi:10.1136/ard.2010.140533

140. Karin M, Gallagher E. From JNK to pay dirt: jun kinases, their biochemistry, physiology and clinical importance. IUBMB Life (2005) 57:283-95. doi:10.1080/15216540500097111

141. Andrade MV, Iwaki S, Ropert C, Gazzinelli RT, Cunha-Melo JR, Beaven MA. Amplification of cytokine production through synergistic activation of NFAT and AP-1 following stimulation of mast cells with antigen and IL-33. Eur J Immunol (2011) 41:760-72. doi:10.1002/eji.201040718

142. Smedler E, Uhlen P. Frequency decoding of calcium oscillations. Biochim Biophys Acta (2014) 1840:964-9. doi:10.1016/j.bbagen.2013.11.015

143. Grodzki AC, Moon KD, Berenstein EH, Siraganian RP. FcepsilonRI-induced activation by low antigen concentrations results in nuclear signals in the absence of degranulation. Mol Immunol (2009) 46:2539-47. doi:10.1016/j. molimm.2009.05.013

144. Rattenbacher B, Bohjanen PR. Evaluating posttranscriptional regulation of cytokine genes. Methods Mol Biol (2012) 820:71-89. doi:10.1007/978-1-61779439-1_5

145. Khabar KS. Post-transcriptional control during chronic inflammation and cancer: a focus on AU-rich elements. Cell Mol Life Sci (2010) 67:2937-55. doi:10.1007/s00018-010-0383-x

146. Palanisamy V, Jakymiw A, Van Tubergen EA, D’silva NJ, Kirkwood KL. Control of cytokine mRNA expression by RNA-binding proteins and microRNAs. J Dent Res (2012) 91:651-8. doi:10.1177/0022034512437372

147. Kontoyiannis D, Pasparakis M, Pizarro TT, Cominelli F, Kollias G. Impaired on/off regulation of TNF biosynthesis in mice lacking TNF AU-rich elements: implications for joint and gut-associated immunopathologies. Immunity (1999) 10:387-98. doi:10.1016/S1074-7613(00)80038-2

148. Brooks SA, Blackshear PJ. Tristetraprolin (TTP): interactions with mRNA and proteins, and current thoughts on mechanisms of action. Biochim Biophys Acta (2013) 1829:666-79. doi:10.1016/j.bbagrm.2013.02.003

149. Gebauer F, Hentze MW. Molecular mechanisms of translational control. Nat Rev Mol Cell Biol (2004) 5:827-35. doi:10.1038/nrm1488

150. Shimobayashi M, Hall MN. Making new contacts: the mTOR network in metabolism and signalling crosstalk. Nat Rev Mol Cell Biol (2014) 15:155-62. doi:10.1038/nrm3757

151. Ma XM, Blenis J. Molecular mechanisms of mTOR-mediated translational control. Nat Rev Mol Cell Biol (2009) 10:307-18. doi:10.1038/nrm2672

152. Park JW, Jeon YJ, Lee JC, Ahn SR, Ha SW, Bang SY, et al. Destabilization of TNF-alpha mRNA by Rapamycin. Biomol Ther (Seoul) (2012) 20:43-9. doi:10.4062/biomolther.2012.20.1.043

153. Thompson SR. Tricks an IRES uses to enslave ribosomes. Trends Microbiol (2012) 20:558-66. doi:10.1016/..tim.2012.08.002 
154. Braunstein S, Karpisheva K, Pola C, Goldberg J, Hochman T, Yee H, et al. A hypoxia-controlled cap-dependent to cap-independent translation switch in breast cancer. Mol Cell (2007) 28:501-12. doi:10.1016/j.molcel.2007.10.019

155. Boesiger J, Tsai M, Maurer M, Yamaguchi M, Brown LF, Claffey KP, et al. Mast cells can secrete vascular permeability factor/vascular endothelial cell growth factor and exhibit enhanced release after immunoglobulin E-dependent upregulation of fc epsilon receptor I expression. J Exp Med (1998) 188:1135-45. doi:10.1084/jem.188.6.1135

156. Jimenez-Andrade GY, Ibarra-Sanchez A, Gonzalez D, Lamas M, GonzalezEspinosa C. Immunoglobulin E induces VEGF production in mast cells and potentiates their pro-tumorigenic actions through a Fyn kinase-dependent mechanism. J Hematol Oncol (2013) 6:56. doi:10.1186/1756-8722-6-56

157. Taganov KD, Boldin MP, Baltimore D. MicroRNAs and immunity: tiny players in a big field. Immunity (2007) 26:133-7. doi:10.1016/j.immuni.2007.02.005

158. Mayoral RJ, Deho L, Rusca N, Bartonicek N, Saini HK, Enright AJ, et al. MiR221 influences effector functions and actin cytoskeleton in mast cells. PLoS One (2011) 6:e26133. doi:10.1371/journal.pone.0026133

159. Taganov KD, Boldin MP, Chang KJ, Baltimore D. NF-kappaB-dependent induction of microRNA miR-146, an inhibitor targeted to signaling proteins of innate immune responses. Proc Natl Acad Sci U S A (2006) 103:12481-6. doi:10.1073/pnas.0605298103

160. Rusca N, Deho L, Montagner S, Zielinski CE, Sica A, Sallusto F, et al. MiR-146a and NF-kappaB1 regulate mast cell survival and Tlymphocyte differentiation. Mol Cell Biol (2012) 32:4432-44. doi:10.1128/MCB.00824-12

161. Biethahn K, Orinska Z, Vigorito E, Goyeneche-Patino DA, Mirghomizadeh F, Foger N, et al. miRNA-155 controls mast cell activation by regulating the PI3Kgamma pathway and anaphylaxis in a mouse model. Allergy (2014) 69:752-62. doi:10.1111/all.12407

162. Xiang Y, Eyers F, Young IG, Rosenberg HF, Foster PS, Yang M. Identification of microRNAs regulating the developmental pathways of bone marrow derived mast cells. PLoS One (2014) 9:e98139. doi:10.1371/journal.pone.0098139

163. Lim PS, Li J, Holloway AF, Rao S. Epigenetic regulation of inducible gene expression in the immune system. Immunology (2013) 139:285-93. doi:10. 1111 /imm. 12100

164. Walczak-Drzewiecka A, Ratajewski M, Pulaski L, Dastych J. DNA methylationdependent suppression of HIF1A in an immature hematopoietic cell line HMC-1. Biochem Biophys Res Commun (2010) 391:1028-32. doi:10.1016/j. bbrc.2009.12.011

165. Walczak-Drzewiecka A, Salkowska A, Ratajewski M, Dastych J. Epigenetic regulation of CD34 and HIF1A expression during the differentiation of human mast cells. Immunogenetics (2013) 65:429-38. doi:10.1007/s00251013-0695-8

166. Monticelli S, Lee DU, Nardone J, Bolton DL, Rao A. Chromatin-based regulation of cytokine transcription in Th2 cells and mast cells. Int Immunol (2005) 17:1513-24. doi:10.1093/intimm/dxh329

167. Hural JA, Kwan M, Henkel G, Hock MB, Brown MA. An intron transcriptional enhancer element regulates IL-4 gene locus accessibility in mast cells. J Immunol (2000) 165:3239-49. doi:10.4049/jimmunol.165.6.3239

168. Kwan M, Powell DR, Nachman TY, Brown MA. An intron GATA-binding site regulates chromatin accessibility and is essential for IL-4 gene expression in mast cells. Eur J Immunol (2005) 35:1267-74. doi:10.1002/eji.200425619

169. El Gazzar M, Yoza BK, Hu JY, Cousart SL, Mccall CE. Epigenetic silencing of tumor necrosis factor alpha during endotoxin tolerance. J Biol Chem (2007) 282:26857-64. doi:10.1074/jbc.M704584200

170. Shurety W, Merino-Trigo A, Brown D, Hume DA, Stow JL. Localization and post-Golgi trafficking of tumor necrosis factor-alpha in macrophages. J Interferon Cytokine Res (2000) 20:427-38. doi:10.1089/107999000312379

171. Murray RZ, Wylie FG, Khromykh T, Hume DA, Stow JL. Syntaxin 6 and Vtilb form a novel SNARE complex, which is up-regulated in activated macrophages to facilitate exocytosis of tumor necrosis Factor-alpha. J Biol Chem (2005) 280:10478-83. doi:10.1074/jbc.M414420200

172. Shurety W, Pagan JK, Prins JB, Stow JL. Endocytosis of uncleaved tumor necrosis factor-alpha in macrophages. Lab Invest (2001) 81:107-17. doi:10.1038/ labinvest.3780216

173. Manderson AP, Kay JG, Hammond LA, Brown DL, Stow JL. Subcompartments of the macrophage recycling endosome direct the differential secretion of IL-6 and TNFalpha. J Cell Biol (2007) 178:57-69. doi:10.1083/jcb.200612131
174. Huse M, Lillemeier BF, Kuhns MS, Chen DS, Davis MM. T cells use two directionally distinct pathways for cytokine secretion. Nat Immunol (2006) 7:247-55. doi:10.1038/ni1304

175. Reefman E, Kay JG, Wood SM, Offenhauser C, Brown DL, Roy S, et al. Cytokine secretion is distinct from secretion of cytotoxic granules in NK cells. J Immunol (2010) 184:4852-62. doi:10.4049/jimmunol.0803954

176. Stanley AC, Lieu ZZ, Wall AA, Venturato J, Khromykh T, Hamilton NA, et al. Recycling endosome-dependent and -independent mechanisms for IL10 secretion in LPS-activated macrophages. J Leukoc Biol (2012) 92:1227-39. doi:10.1189/jlb.0412191

177. Lacy P, Stow JL. Cytokine release from innate immune cells: association with diverse membrane trafficking pathways. Blood (2011) 118:9-18. doi:10.1182/ blood-2010-08-265892

178. Pagan JK, Wylie FG, Joseph S, Widberg C, Bryant NJ, James DE, et al. The t-SNARE syntaxin 4 is regulated during macrophage activation to function in membrane traffic and cytokine secretion. Curr Biol (2003) 13:156-60. doi:10.1016/S0960-9822(03)00006-X

179. Low PC, Misaki R, Schroder K, Stanley AC, Sweet MJ, Teasdale RD, et al. Phosphoinositide 3-kinase delta regulates membrane fission of Golgi carriers for selective cytokine secretion. J Cell Biol (2010) 190:1053-65. doi:10.1083/jcb. 201001028

180. Laffargue M, Ragab-Thomas JM, Ragab A, Tuech J, Missy K, Monnereau L, et al. Phosphoinositide 3-kinase and integrin signalling are involved in activation of Bruton tyrosine kinase in thrombin-stimulated platelets. FEBS Lett (1999) 443:66-70. doi:10.1016/S0014-5793(98)01680-9

181. Pachlopnik Schmid J, Cote M, Menager MM, Burgess A, Nehme N, Menasche $\mathrm{G}$, et al. Inherited defects in lymphocyte cytotoxic activity. Immunol Rev (2010) 235:10-23. doi:10.1111/j.0105-2896.2010.00890.x

182. Sánchez-Guiu I, Torregrosa JM, Velasco F, Antón AI, Lozano ML, Vicente V, et al. Hermansky-Pudlak syndrome. Overview of clinical and molecular features and case report of a new HPS-1 variant. Hamostaseologie (2014) 34. doi:10.5482/HAMO-14-06-0024

183. Clark R, Griffiths GM. Lytic granules, secretory lysosomes and disease. Curr Opin Immunol (2003) 15:516-21. doi:10.1016/S0952-7915(03) 00113-4

184. Hammel I, Dvorak AM, Galli SJ. Defective cytoplasmic granule formation. I. Abnormalities affecting tissue mast cells and pancreatic acinar cells of beige mice. Lab Invest (1987) 56:321-8.

185. Chi EY, Ignacio E, Lagunoff D. Mast cell granule formation in the beige mouse. J Histochem Cytochem (1978) 26:131-7. doi:10.1177/26.2.624833

186. Dvorak AM, Hammel I, Galli SJ. Beige mouse mast cells generated in vitro: ultrastructural analysis of maturation induced by sodium butyrate and of IgEmediated, antigen-dependent degranulation. Int Arch Allergy Appl Immunol (1987) 82:261-8. doi:10.1159/000234202

187. Di Pietro SM, Falcon-Perez JM, Tenza D, Setty SR, Marks MS, Raposo G, et al. BLOC-1 interacts with BLOC-2 and the AP-3 complex to facilitate protein trafficking on endosomes. Mol Biol Cell (2006) 17:4027-38. doi:10.1091/mbc.E06-05-0379

188. Oberhauser AF, Fernandez JM. A fusion pore phenotype in mast cells of the ruby-eye mouse. Proc Natl Acad Sci U S A (1996) 93:14349-54. doi:10.1073/ pnas.93.25.14349

189. Ryan JJ, Kashyap M, Bailey D, Kennedy S, Speiran K, Brenzovich J, et al. Mast cell homeostasis: a fundamental aspect of allergic disease. Crit Rev Immunol (2007) 27:15-32. doi:10.1615/CritRevImmunol.v27.i1.20

190. Malbec O, Daeron M. The mast cell IgG receptors and their roles in tissue inflammation. Immunol Rev (2007) 217:206-21. doi:10.1111/j.1600-065X. 2007.00510.x

191. Blank U, Launay P, Benhamou M, Monteiro RC. Inhibitory ITAMs as novel regulators of immunity. Immunol Rev (2009) 232:59-71. doi:10.1111/j.1600065X.2009.00832.x

192. Peachell P. Regulation of mast cells by beta-agonists. Clin Rev Allergy Immunol (2006) 31:131-42. doi:10.1385/CRIAI:31:2:131

193. Madera-Salcedo IK, Cruz SL, Gonzalez-Espinosa C. Morphine prevents lipopolysaccharide-induced TNF secretion in mast cells blocking IkappaB kinase activation and SNAP-23 phosphorylation: correlation with the formation of a beta-arrestin/TRAF6 complex. J Immunol (2013) 191:3400-9. doi:10.4049/jimmunol.1202658 
Conflict of Interest Statement: The authors declare that the research was conducted in the absence of any commercial or financial relationships that could be construed as a potential conflict of interest.

Received: 01 August 2014; accepted: 05 September 2014; published online: 22 September 2014.

Citation: Blank U, Madera-Salcedo IK, Danelli L, Claver J, Tiwari N, SánchezMiranda E, Vázquez-Victorio G, Ramírez-Valadez KA, Macias-Silva Mand GonzálezEspinosa C (2014) Vesicular trafficking and signaling for cytokine and chemokine secretion in mast cells. Front. Immunol. 5:453. doi: 10.3389/fimmu.2014.00453
This article was submitted to Molecular Innate Immunity, a section of the journal Frontiers in Immunology.

Copyright (c) 2014 Blank, Madera-Salcedo, Danelli, Claver, Tiwari, Sánchez-Miranda, Vázquez-Victorio, Ramírez-Valadez, Macias-Silva and González-Espinosa. This is an open-access article distributed under the terms of the Creative Commons Attribution License (CC BY). The use, distribution or reproduction in other forums is permitted, provided the original author(s) or licensor are credited and that the original publication in this journal is cited, in accordance with accepted academic practice. No use, distribution or reproduction is permitted which does not comply with these terms. 